\title{
Indonesians Human Leukocyte Antigen (HLA) Distributions and Correlations with Global Diseases
}

\section{Krisnawan Andy Pradana, Michael Anekson Widjaya \& Mariana Wahjudi}

To cite this article: Krisnawan Andy Pradana, Michael Anekson Widjaya \& Mariana Wahjudi (2020) Indonesians Human Leukocyte Antigen (HLA) Distributions and Correlations with Global Diseases, Immunological Investigations, 49:3, 333-363, DOI: 10.1080/08820139.2019.1673771

To link to this article: https://doi.org/10.1080/08820139.2019.1673771

\section{曲 Published online: 24 Oct 2019.}

Submit your article to this journal $\widetilde{x}$

\section{Џ Article views: 45}

\section{Q View related articles $\asymp$}

View Crossmark data \lceil

Citing articles: 1 View citing articles $\sqsubset$ 


\title{
Indonesians Human Leukocyte Antigen (HLA) Distributions and Correlations with Global Diseases
}

\author{
Krisnawan Andy Pradana (10), Michael Anekson Widjayaa, and Mariana Wahjudi $\mathbb{1}^{\mathrm{a}}$ \\ ${ }^{a}$ Faculty of Biotechnology, University of Surabaya, Surabaya City, Indonesia; ${ }^{b}$ Department of Anatomy and \\ Histology Faculty of Medicine, Airlangga University, Tambaksari, Surabaya City, Indonesia
}

\begin{abstract}
In Human, Major Histocompatibility Complex known as Human Leukocyte Antigen (HLA). The HLA grouped into three subclasses regions: the class I region, the class II region, and the class III region. There are thousands of polymorphic HLAs, many of them are proven to have correlations with diseases. Indonesia consists of diverse ethnicity people and populations. It carries a unique genetic diversity between one and another geographical positions. This paper aims to extract Indonesians HLA allele data, mapping the data, and correlating them with global diseases. From the study, it is found that global diseases, like Crohn's disease, rheumatoid arthritis, Graves' disease, gelatin allergy, T1D, HIV, systemic lupus erythematosus, juvenile chronic arthritis, and Mycobacterial disease (tuberculosis and leprosy) suspected associated with the Indonesian HLA profiles.
\end{abstract}

\section{KEYWORDS}

HLA; Allele; Indonesia; global disease

\section{Introduction}

The Human Leukocyte Antigens (HLAs) are grouped into three subclasses regions: the class I, II and III regions. The class I region, the classical group contains highly polymorphic $H L A-A$, $H L A-B$, and $H L A-C$ genes, and the nonclassical exhibits limited polymorphism, i.e. HLA-E, $H L A-F$ and $H L A-G$ genes. The class II region, involved in antigen processing and presentation, consists of the HLA-DPA1, HLA-DPB1, HLA-DQA1, HLA-DQA2, HLA-DQB1, HLA-DQB2, HLA-DRA, HLA-DRB1, HLA-DRB2, HLA-DRB3, HLA-DRB4 and HLA-DRB5 genes. The class III region, contains genes implicated in inflammatory responses, leukocyte maturation and the complement cascade (Dendrou et al. 2018). Many cases are associated with the HLA profiles, and more cases are found since the first discovery of Hodgkin Lymphoma is related to HLA-B profile (Amiel 1967). As mentioned before, HLA contains regions that carrying highly polymorphic genes and those unique characteristic makes HLA precisely fit within its interaction through immunology view. Those highly polymorphic genes sequences leads to the invention of HLA profiles by several generations methods for determination the alleles in an individual person: PCR-RFLP, SSOP, immobilized probes, PCR-SSP, Sanger sequencing, and lately Next Generation Sequencing (NGS) (Carapito et al. 2016; Erlich 2012; Hosomichi et al. 2015; Kishore and Petrek 2018). From the data mining through thousands of research on HLA, now the big data are available. This large data can be translated not only for genome mapping but also can be used for connecting between allele type with diseases, allele type with genome

CONTACT Mariana Wahjudi mariana_wahyudi@staff.ubaya.ac.id $\mathrm{E}$ Faculty of Biotechnology, University of Surabaya, Raya Kali Rungkut Rd, Surabaya City, East Java 60293, Indonesia

Present affiliation for Michael Anekson Widjaya is Department of Biotechnology, Asia University, Wufeng District, Taichung, Taiwan. 
defect by natural selections (Meyer et al. 2018). With the fact that specific alleles have correlations with specific diseases comes together as information for susceptibility of illness preventive medication. Indonesia is the fourth most significant populations in the world, with more than 268,361,538 people (Indonesia Population 2019; Anonim 2019). Until now, no information about HLA correlation with disease on Indonesian populations. This research aims to extract Indonesians HLA allele data, mapping the data, and correlating with global diseases so at the end of the research could be used as the basics information of Indonesians HLA alleles associated with diseases.

\section{Indonesians HLA data}

Indonesia is an ethnic, race, and cultural group diverse population. As mentioned before, with more than 268 million citizens and divided into 34 provinces in total, Indonesia becomes the place where the various gene can be found. Indonesian HLA allele frequencies were recorded, the late study in 2010 (Yuliwulandari et al. 2010b). Data from the Indonesians HLA database (AlleleFrequency.net), from 9 research data in total (Moluccan Island (Maluku), Central Java, West Java, Nusa Tenggara Island, and Indonesia Singaporean) will be extracted and clustered by the allele type (Anonim, 2019; Charron et al., 1997; Gao et al. 1992; Gao and Matheson 1996; Mack et al. 2000; Meyer et al. 2018; Nagy et al. 2007; Yuliwulandari et al. 2009, 2010a, 2010b, 2017; Zimdahl et al. 1999).

\section{HLA associations with diseases}

The HLA genes involved in antigen processing and presentation The class III region contains genes implicated in inflammatory responses, leukocyte maturation and the complement cascade (Dendrou et al. 2018). The T cells receive the peptide from HLA class I and II molecules to discriminate between self and non-self (Murphy 2014). More than thousands of variations of HLA class I and II alleles have been reported in IMGT - HLA database (Robinson et al. 2016). Those variations of HLA genes give us more insight on how does the diseases correlated by the presentation of HLA molecules (peptide) to the immune cells. The polymorphism of HLA molecules drives to the variations of the peptide binding structure. For example, Trp at position 156 in $H L A-B^{\star} 35: 62$ was shown to confer a TAPindependent (antigen presentation complex) mode of peptide loading. This could be suggestive of consulting the ability of peptide presentation via non-classical pathways and its potential role in immune response against viral infections (Manandhar et al. 2016). The specific recognition of HLA-peptide combinations is mediated by a $\beta$ T cell receptors (TCRs) on $\mathrm{CD}^{+} \mathrm{T}$ cells, which bind class I molecules, and on $\mathrm{CD} 4^{+} \mathrm{T}$ cells, which bind class II molecules. The TCR displays substantial sequence heterogeneity that arises as the different variable (V), diversity (D) and joining (J) gene segments come together through somatic, convergent recombination; additional variation is introduced by the semi-random insertion or deletion of nucleotides at segment junctions (Quigley et al. 2010). Furthermore, each TCR chain contains three highly variable complementarity determining region (CDR) loops: CDR1 and CDR2 diversity is germline-encoded, whereas the CDR3 loop is hypervariable, as it are encoded by the sequences generated by nucleotide insertion and deletion. Finetuning of lymphocyte activity is gained by molecules belonging to two different classes of class I specific complex histocompatibility complex (MHC) inhibitory receptors. While killer 
immunoglobulin-receptors (KIR) are integral type I membrane proteins that interact with certain human leukocyte antigens (HLA) -A, HLA-B, or HLA-C alleles, receptors that killer lectin resemble cells (KLR) represent membrane proteins type II integral of type C lectin family (Eberl et al. 2005). There are kind of mechanism to know how HLA initiate disease, first, HLA-peptide-TCR binding, second, epitope variation, including molecular mimicry, post-translational epitope modification and the generation of hybrid peptides; in further and deep explanation, molecular mechanism which are involved including alternate docking, low-affinity-mediated thymic escape, $\mathrm{T}$ cell receptor stabilization of weak peptide-HLA complexes, altered register, 'Hotspot' molecular mimicry, post-translational modification, hybrid peptides, regulation of HLA expression, and HLA stability (Dendrou et al. 2018).

\section{Global diseases correlated with HLA profile}

In a worldwide view, HLA molecules do not only act as graft uses nor immunology things. HLA could be used as a marker of the possibility on the appearance of any diseases. From the latest review and research article exist on the database, we collect the associations between HLA profile with diseases. Since the previous explanations about how the HLA molecules give an effect on disease through its molecular mechanism of action, now we can truly understand everything about the mechanism itself in many diseases (Table 1). There will be an explanation what type of disease, how the effect on disease, molecular mechanism, and actions among the literature that exists (Dendrou et al. 2018). While on previous explanation was talking about the arrangement, in other research found the HLA allele associated with the appearance of diseases and it potential to influence the disease borne Table 2

\section{Global disease HLA profile as representation of indonesian HLA allele coherence}

The mechanism of HLA on disease was clearly explained (Dendrou et al. 2018). Indonesia has a great problem related to HLA database due to disease research. This problem can be solved by general relating between Indonesian allele and the global disease related with HLA profile. From the previous research and the HLA data collected (Tables 1 \& 2), the diseases like Crohn's disease, rheumatoid arthritis, Graves' disease, gelatin allergy, T1D, HIV, systemic lupus erythematosus, juvenile chronic arthritis, and Mycobacterial disease (tuberculosis and leprosy) suspected to be associated in the Indonesian HLA profiles. More specific, the alleles give some clue of disease deployment (Table 4). The output could be translated into variated applications, such as drugs design (including cellular and noncellular therapy), and graft transplant susceptibility.

\section{Indonesia HLA profile correlated with diseases}

From the literatures of 1000 original research articles searched using Taylor and Francis, Google Scholar, SCOPUS, and PubMed, the 19 articles were selected, processed and extracted (Table 3). From the study, pulmonary tuberculosis, elephantiasis, spondyloarthropathy (SpA), leprosy, ankylosing spondylitis, chronic and occult hepatitis B infection, $H$. pylori infection, and Steven-Johnson syndrome/toxic epidermal necrolysis are identified as diseases that correlated with HLA. Indonesia as the one of 22 countries with high Tuberculosis (TB) prevalence, 


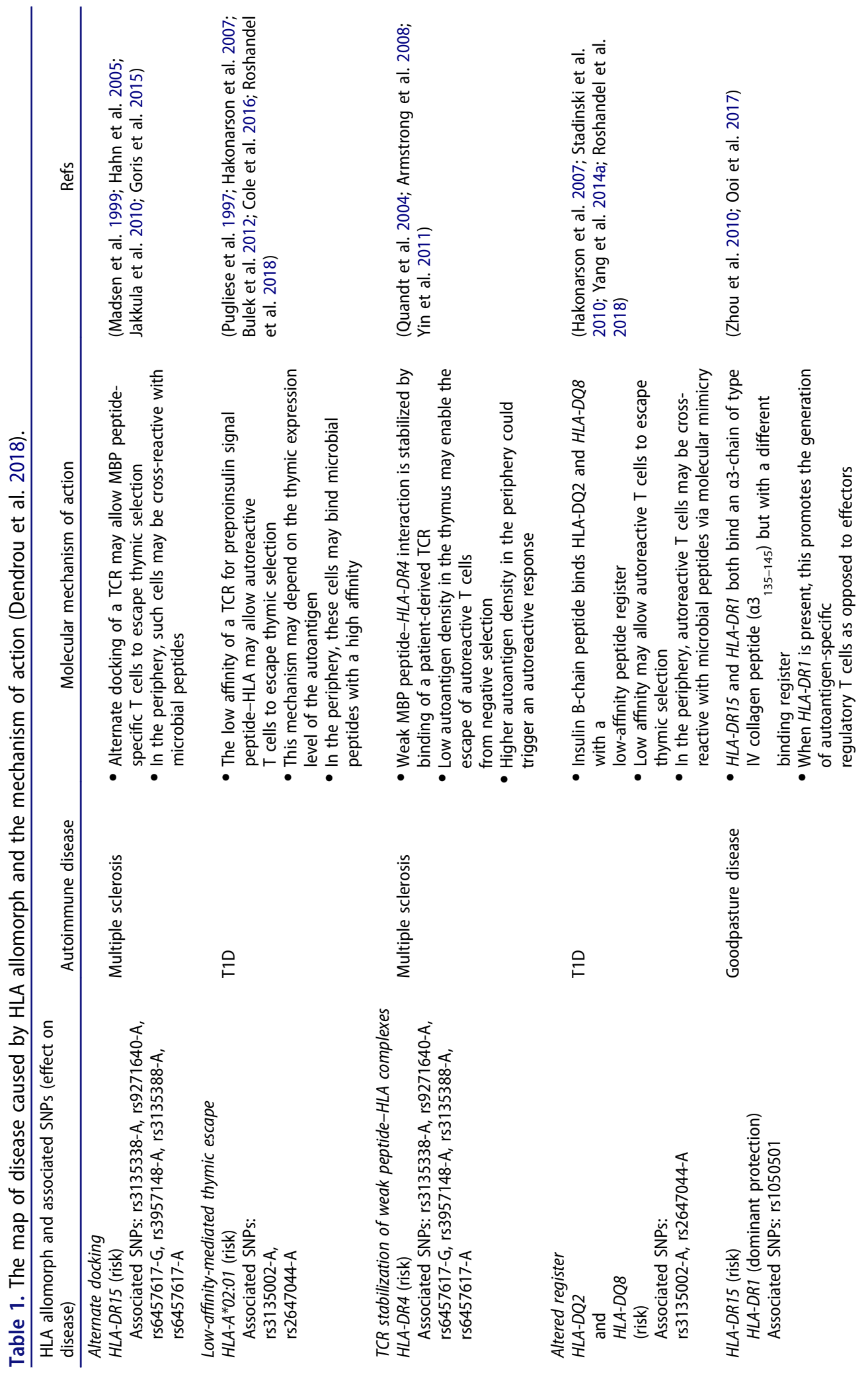




\begin{tabular}{|c|c|c|c|c|c|}
\hline 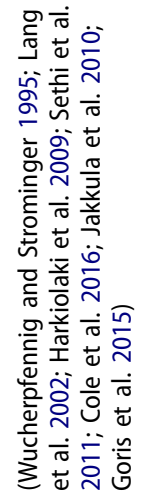 & 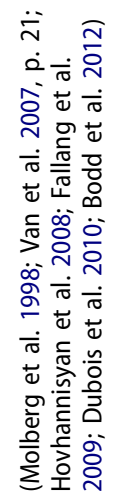 & 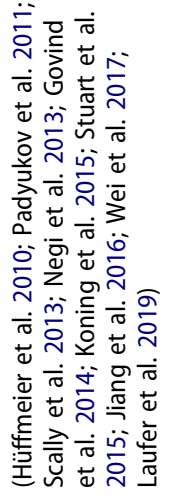 & 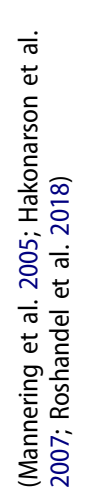 & 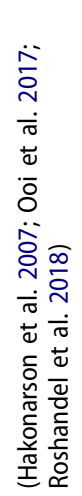 & 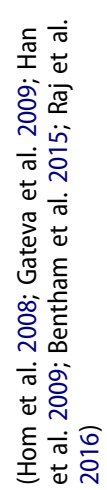 \\
\hline
\end{tabular}
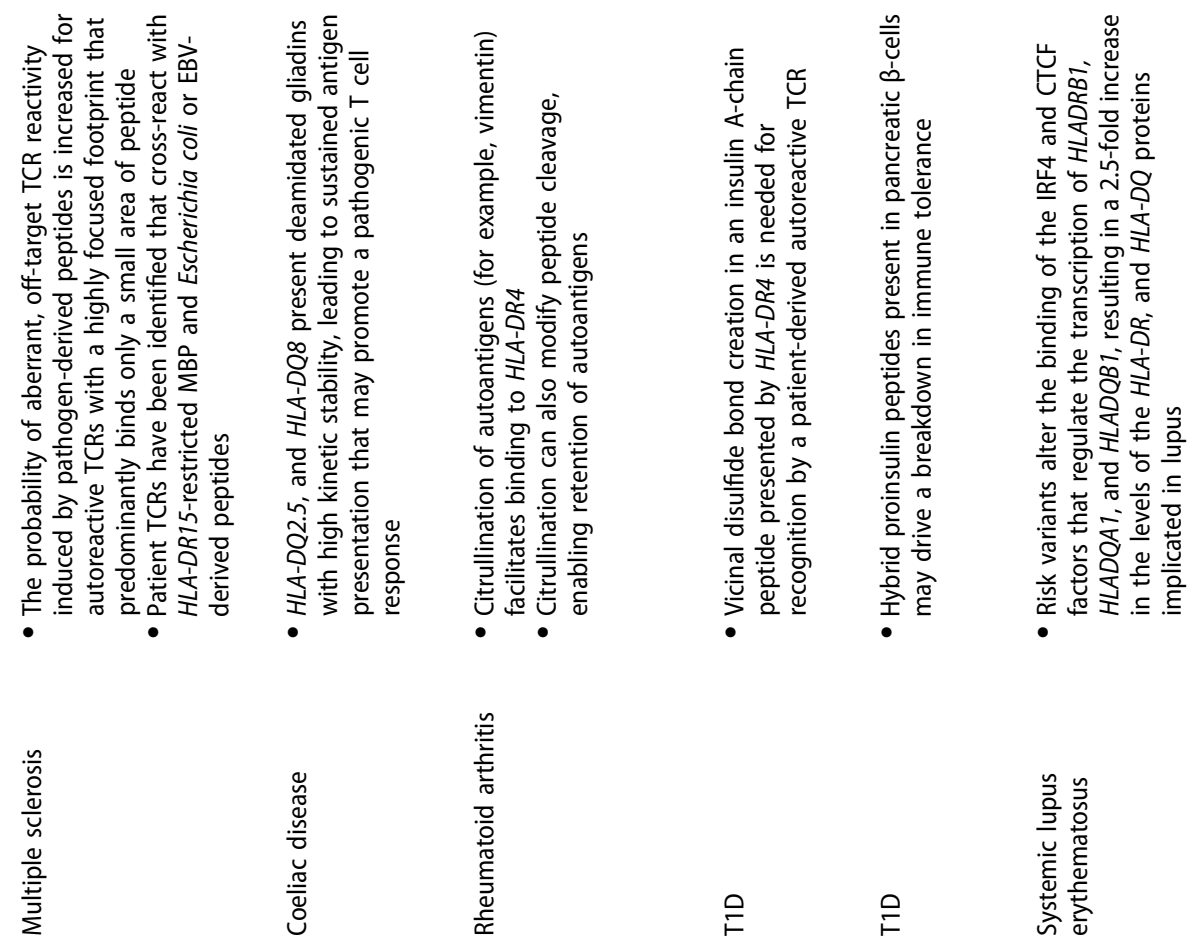

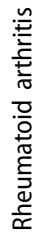
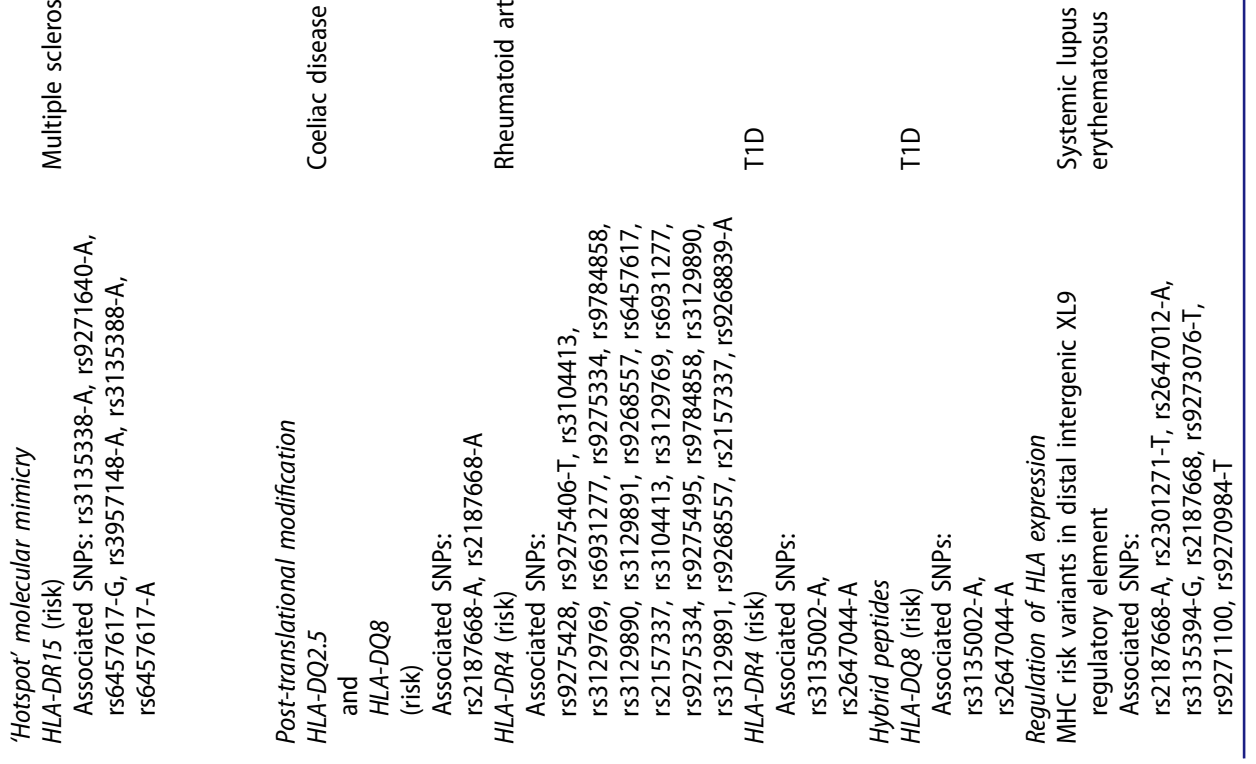


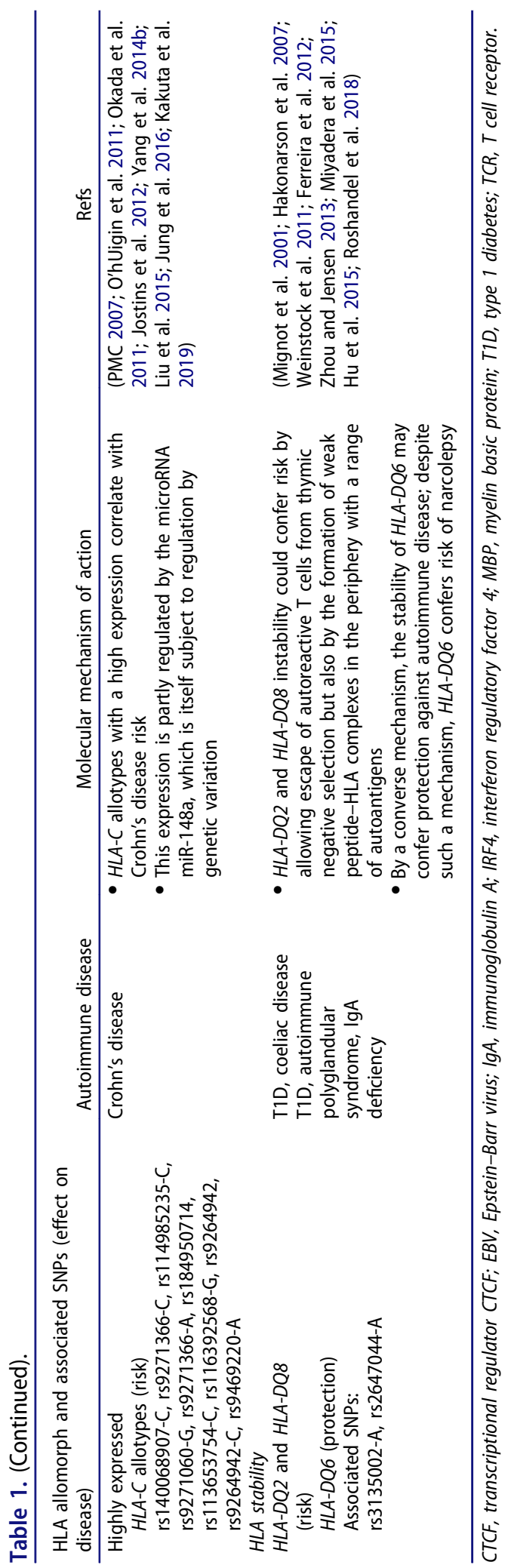




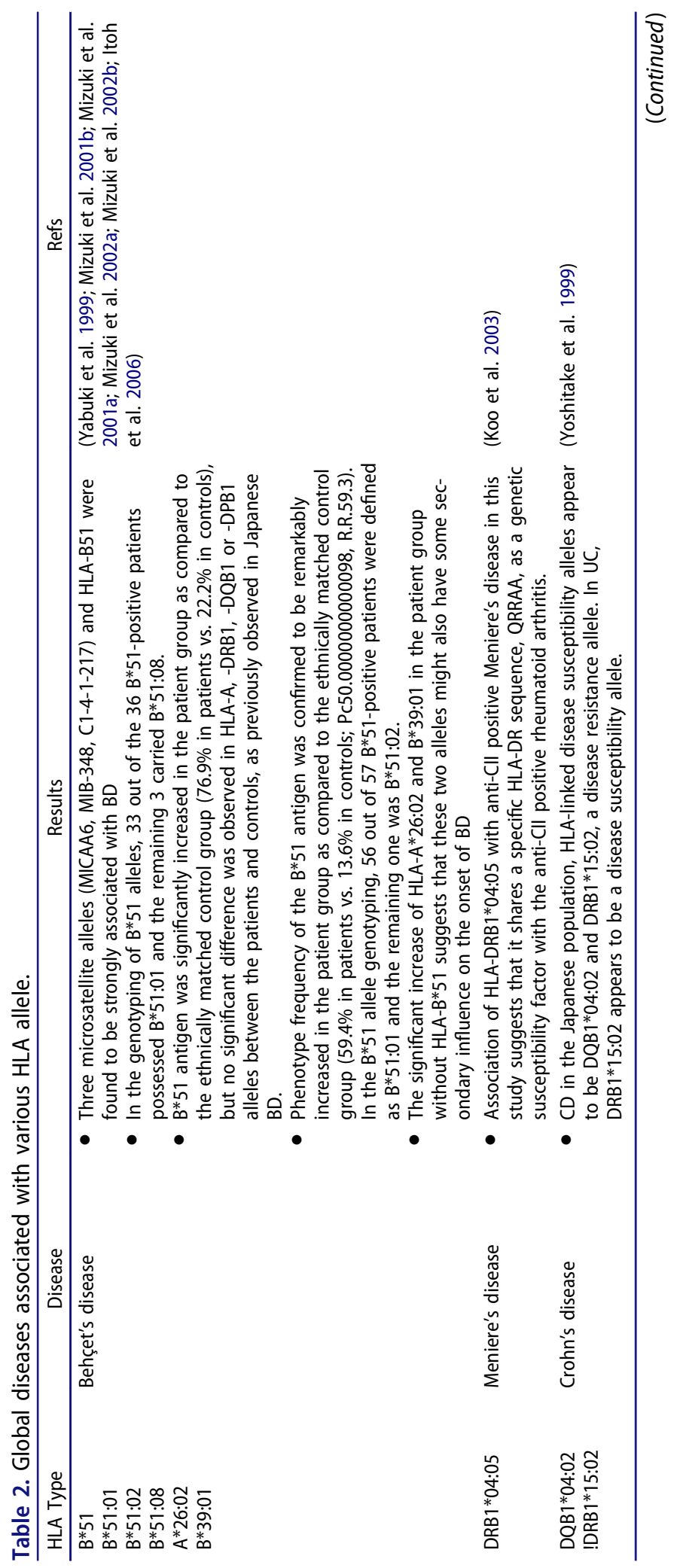




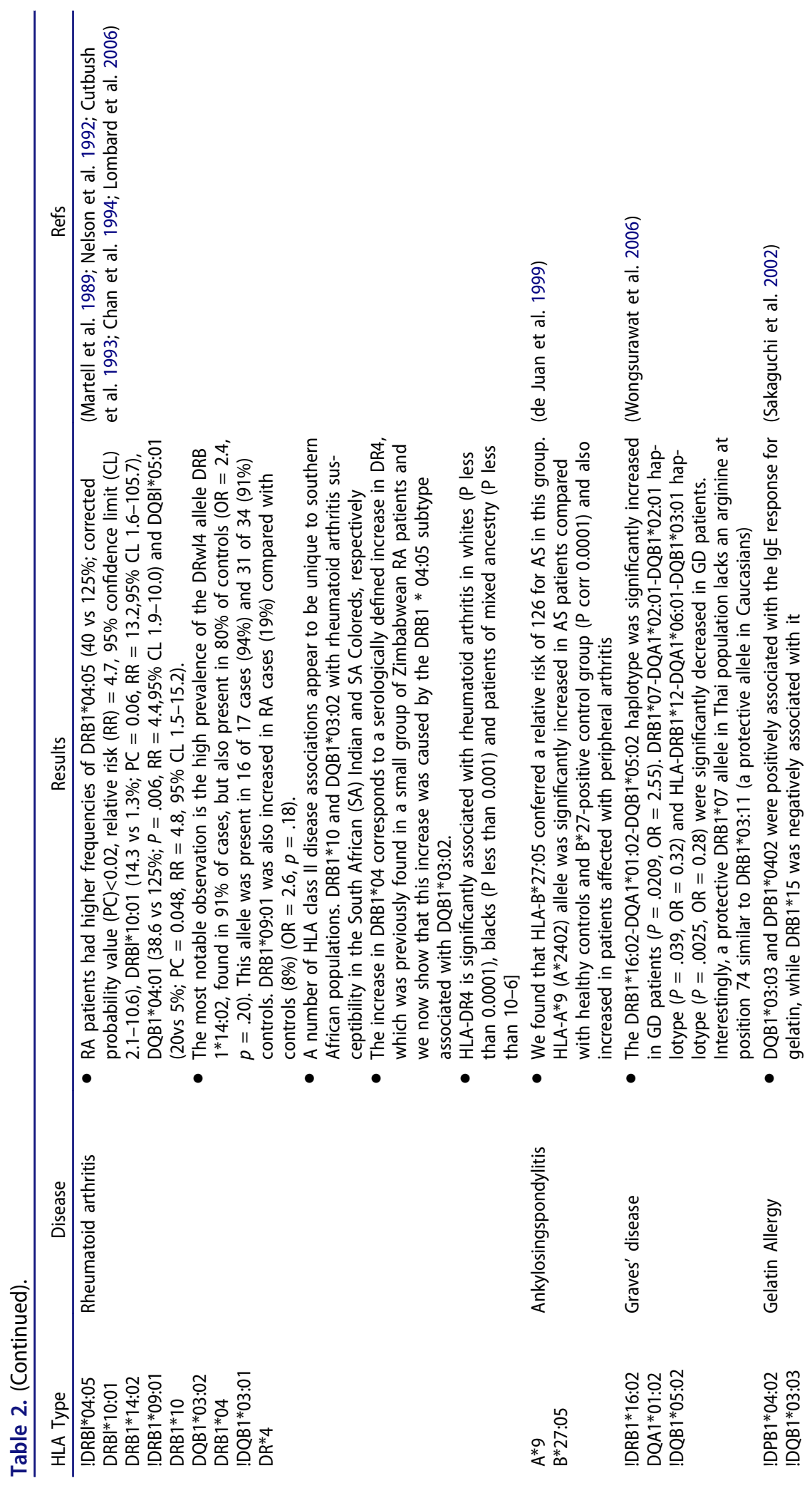




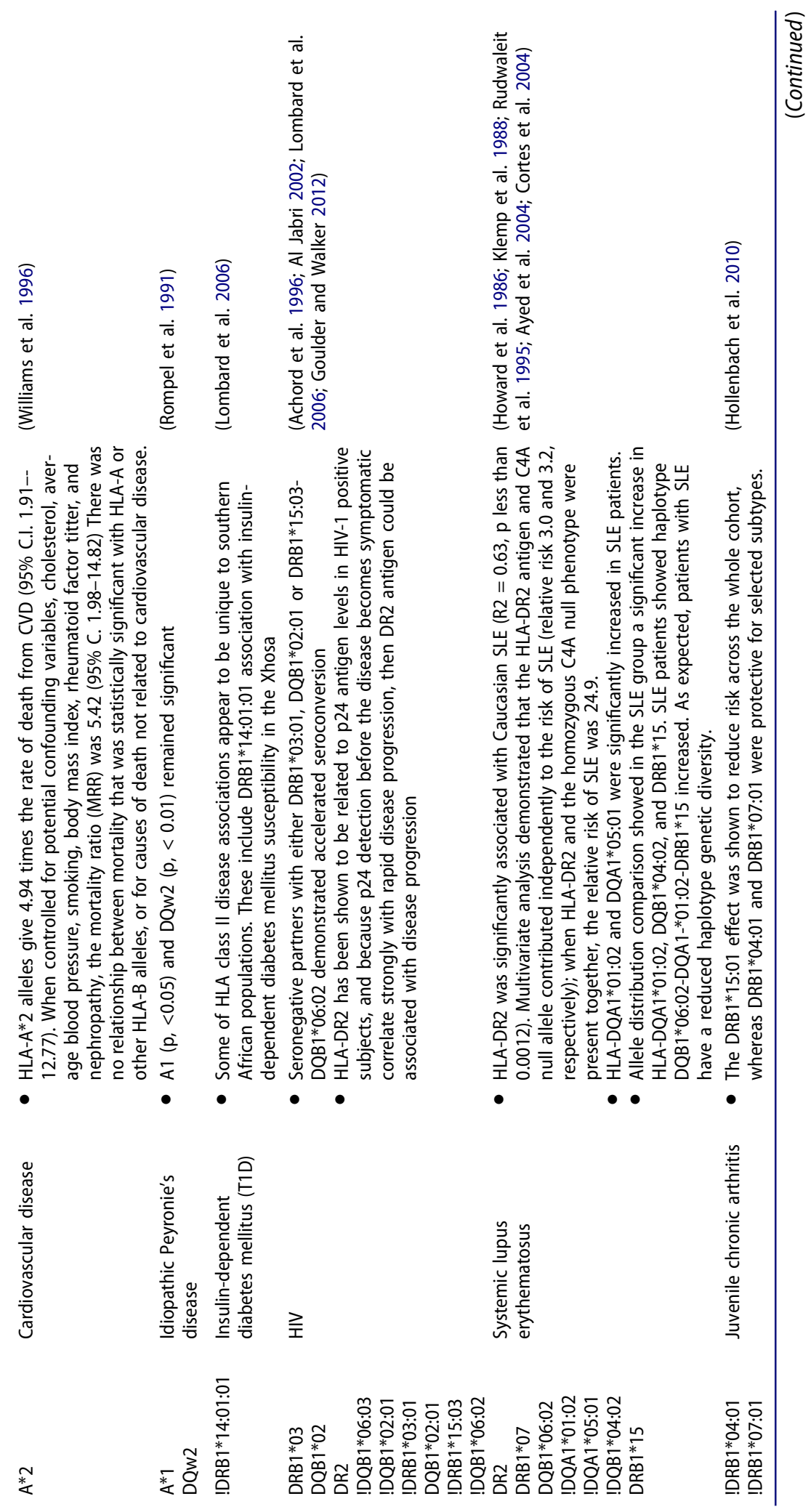




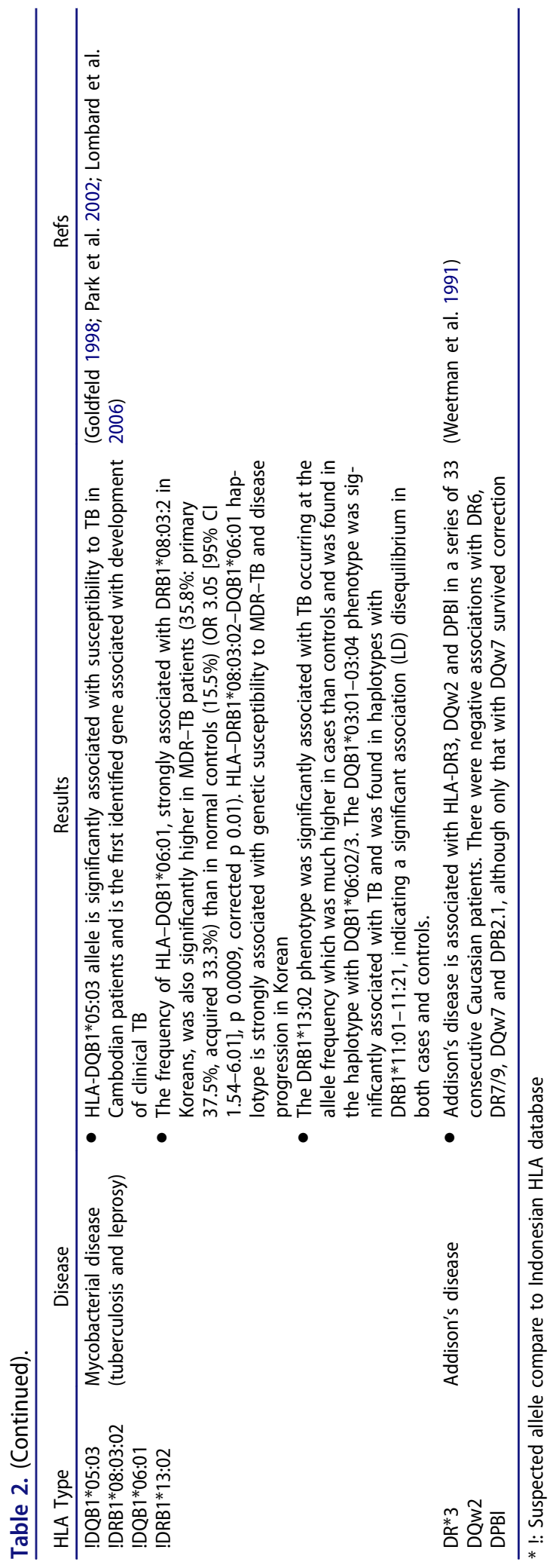


reported there are 1.017.378 active patient (Collins et al. 2017). Those number of TB patients contrast with the research of HLA correlation with TB in Indonesia. In 2017, a total 12.677 patient recorded for having elephantiasis and the highest number is for Papua Island (Harpini 2018). High prevalence of those diseases and lack of information makes researcher and academician turn in concern of this subject. As early detection, HLA could be used as important molecular marker and statistically associated for any diseases such as diabetes, hepatitis B virus infection, breast cancer, Behçet's, tuberculosis, spondyloarthropathy, leprosy, ankylosing spondylitis, H. pylori infection, and Steven-Johnson syndrome (Chen et al. 2017; Ding et al. 2010; Elfishawi et al. 2019; Gönen et al. 2017; Hajjej et al. 2019; Kankonkar and Shankarkumar 2008; Khor et al. 2017; Krause-Kyora et al. 2018; Matei et al. 2018; Ouni et al. 2019; Smith 2013)

\section{Indonesia HLA profile}

Indonesia HLA profile is similar to people in South East Asia because they have high frequency variation in $H L A-B^{\star} 15: 02$ and $H L A-D R B 1^{\star} 12$ :02 especially for Javanese, Mollucan, and Nusa Tenggara people (Sanchez-Mazas et al. 2005; Yuliwulandari et al. 2010a). Unfortunately, not all Indonesian people is typed on HLA variably. Almost West Javanese have been typed (Yuliwulandari et al. 2009, 2017, 2010a, 2010b). Only few populations that have been done outside West Javanese which are Yogyakarta, Molluca, and Nusa Tenggara people (Gao et al. 1992; Sanchez-Mazas et al. 2005). In other hand, from single nucleotide polimorphism (SNP) genome wide association study (GWAS), Indonesia carry an unique genetic diversity between one and another geographical position (Hudjashov et al. 2017).

The closest ethnicity with Indonesian ethnics is Malaysian and other South East Asian countries (Figure 1). It happens because there were two different era groups which were 40,000 BP and 6000-5000 BP migrated to Indonesian region (Yuliwulandari et al. 2010a). The first group migrated from Indian subcontinent through Indo-Malaysian archipelago. At that time, Indonesia was divided into 3 islands which were Greater Sunda Land, Wallacea, and Sahul Island. Later, the second group which was Austronesian moved into Java and forced the first group to move away to Oceania although there was

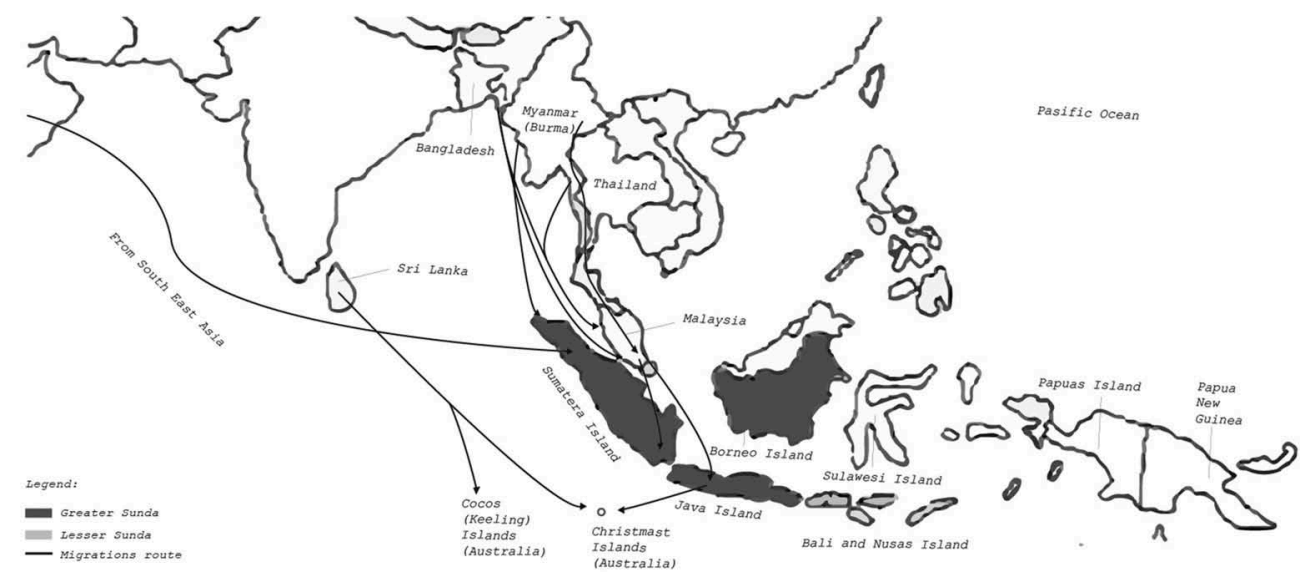

Figure 1. An illustrated geographical migrations map of South East Asia and Indonesian populations. 


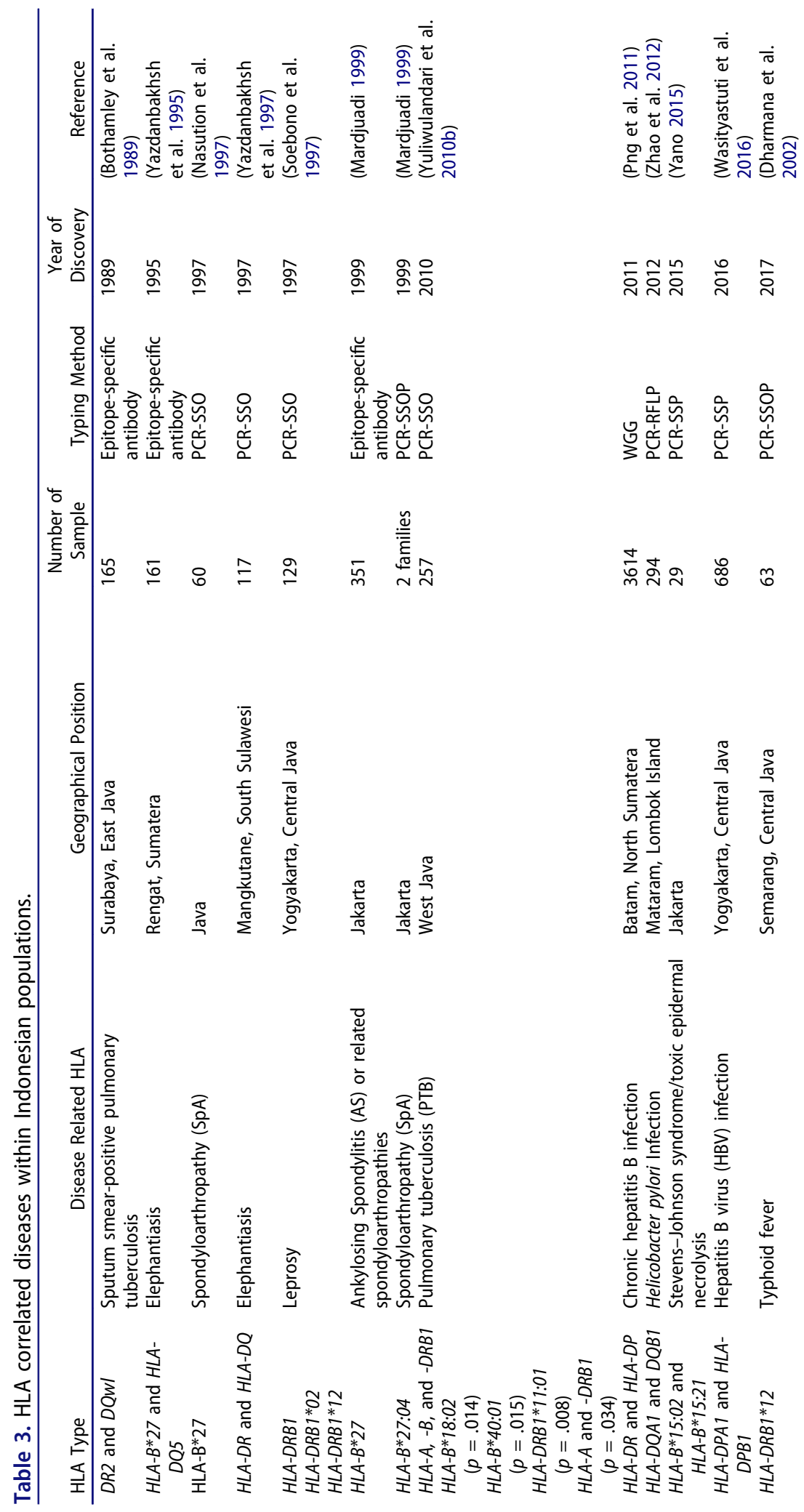




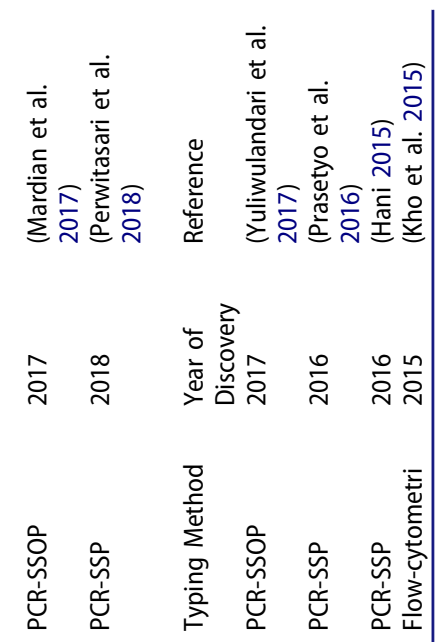

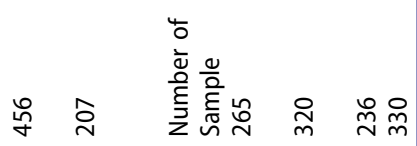
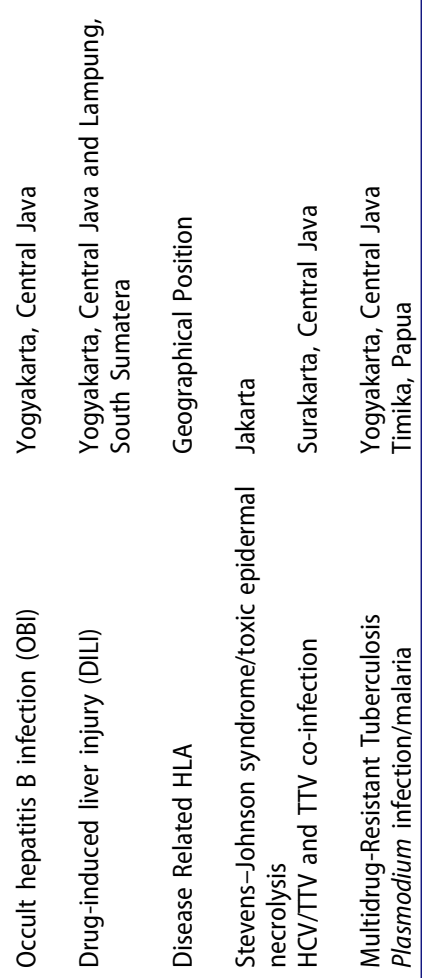

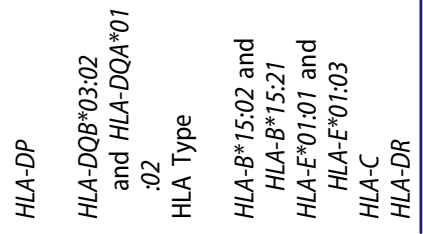


a possbility that the first group might blend together with the second group. The second group later predominates West Indonesia region and later become Javanese. This is the reason why Indonesia genetic is similar to Malaysia since Malaysia is also considered as Austronesian based on Sanchez-Mazas research (Sanchez-Mazas et al. 2005). This theory is also proved by occurrence of $H L A-A^{\star} 3401$ that a sign for the first group existence in Indonesia (Yuliwulandari et al. 2010a).

Although Indonesia has similarity with South East Asian countries, but Indonesia still has unique HLA characteristics. Yogyakarta people tend to have high frequency at $D Q A 1^{\star} 06: 01, D Q B 1^{\star} 03: 01, D R B 1^{\star} 12: 02$ (Gao et al. 1992) and Western Javanese people have $H L A-A^{\star} 2407$ (Yuliwulandari et al. 2010b). Those HLA regions are not familiar in other countries which are needed to be confirmed using different Indonesian ethnicity.

\section{Indonesia HLA profile correlation with global disease}

Based on Table 4, Indonesia HLA profile has high variation at $D Q A 1^{\star} 06: 01, D Q B 1^{\star} 03: 01$, $D R B 1^{\star} 12: 02, H L A-A^{\star} 24: 07, H L A-B^{\star} 15: 02, H L A-B^{\star} 75, H L A-B^{\star} 18: 02$. Those alleles are significant in researches statistical model (Yuliwulandari et al. 2009, 2017, 2010a, 2010b). Further research is important to explore those alleles because those alleles have roles in diseases, except $D Q A 1^{*} 06: 01$ (Table 4). Other alleles in Table 4 still have not been known whether it will affect Indonesian health condition or not but, in another countries, based on Global-Allele frequency.net, some of alleles affect human health condition.

For example, $H L A-A^{\star} 02: 01: 01: 01, H L A-A^{\star} 02: 03: 01, H L A-A^{\star} 02: 06: 01, H L A-A^{\star} 02: 11$ in Table 4 show variation in Javanese but nobody have done research regarding those alleles correlation with many diseases as Rasmussen encephalitis (RE), carbamazepine-induced hypersensitivity reactions and also for vaccine development amongst Indonesian (Dandekar et al. 2016; Maira et al. 2014; Song et al. 2013; Zhang et al. 2018). Therefore, further research is needed to be done because it has potential might affect Indonesian. Another case is $D Q A 1^{\star} 06: 01$. This allele is related with rheumatoid arthritis (Table 4). However, nobody has done the research for Indonesian because that allele is found for anthropology purpose at that time (Gao et al. 1992). Otherwise, The most unique Indonesian HLA, HLA- $A^{\star}$ 24:07 (Yuliwulandari et al. 2010a), is related to Diabetes type 1 (Ghodke et al. 2005) but there is no research about Indonesia Diabetes type 1 patient and that allele relationship.

Current research that has been done is $H L A-B^{\star} 15: 02$ and $H L A-B^{\star} 75$. It shows that those alleles are connected to Steven Johnson Syndrome. The research suggests $H L A-B^{\star} 75$ is needed to be further explored because it affects the disease more than $H L A-B^{\star} 15: 02$. Other research that has been done is the correlation between HLA and tuberculosis disease (Yuliwulandari et al. 2010a). The result shows the most affective HLA alleles that affect tuberculosis disease are $H L A-B^{\star} 18: 02$ and $H L A-D R B 1^{\star} 12: 02$. It has potential to protect the patient against tuberculosis disease. Nonetheless, the research needs to be done in more samples. As a conclusion, from the Table 3, other than Sputum smear-positive pulmonary tuberculosis, Elephantiasis, Pulmonary tuberculosis (PTB), Ankylosing Spondylitis (AS) or related spondyloarthropathies, chronic hepatitis B infection, Helicobacter pylori infection, Stevens-Johnson syndrome/toxic epidermal necrolysis, hepatitis B virus (HBV) infection, drug-induced liver injury (DILI), HCV/TTV and TTV co-infection, multidrug-resistant tuberculosis, and Plasmodium infection/malaria research, nobody has done the HLA- 


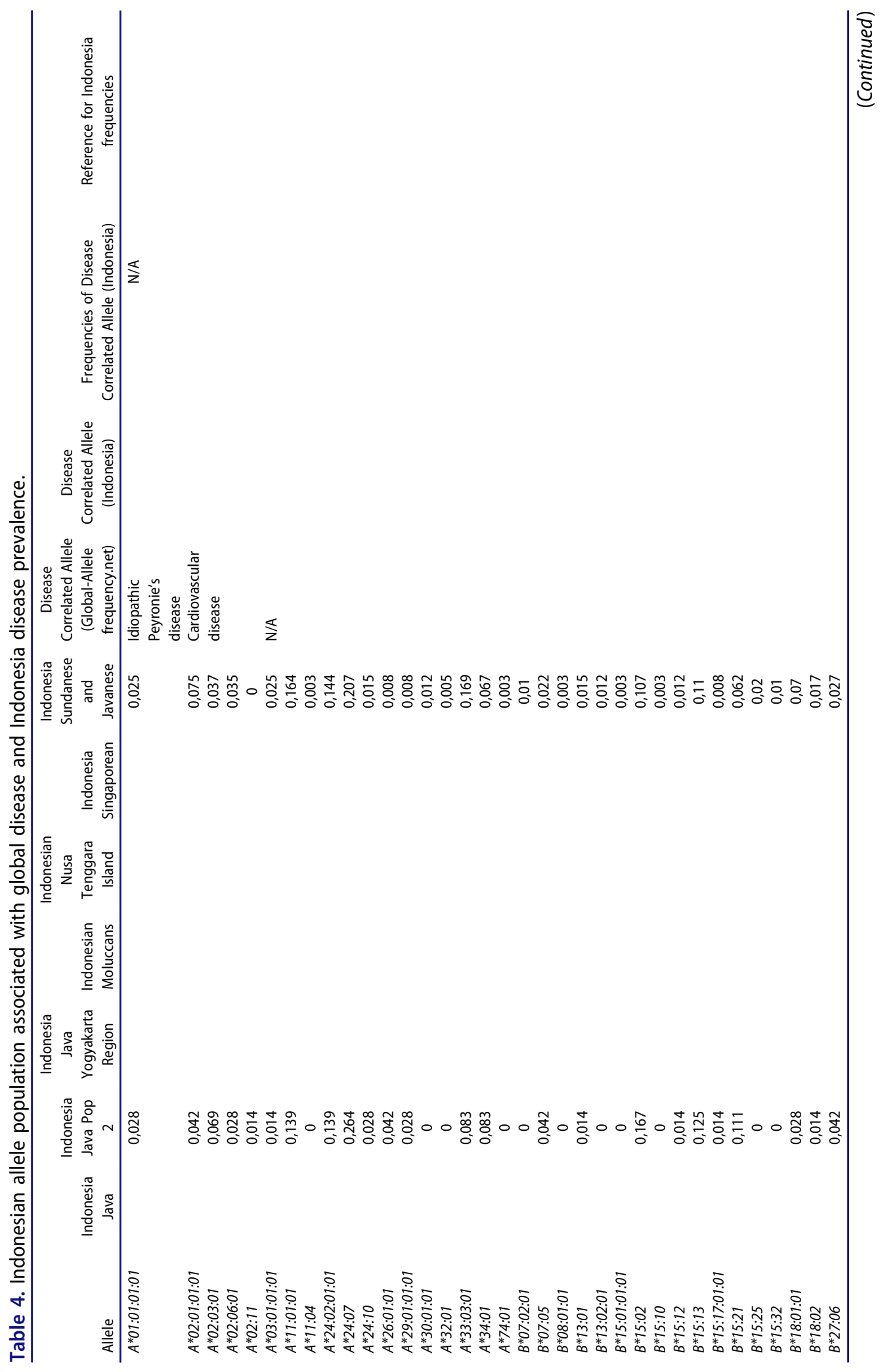




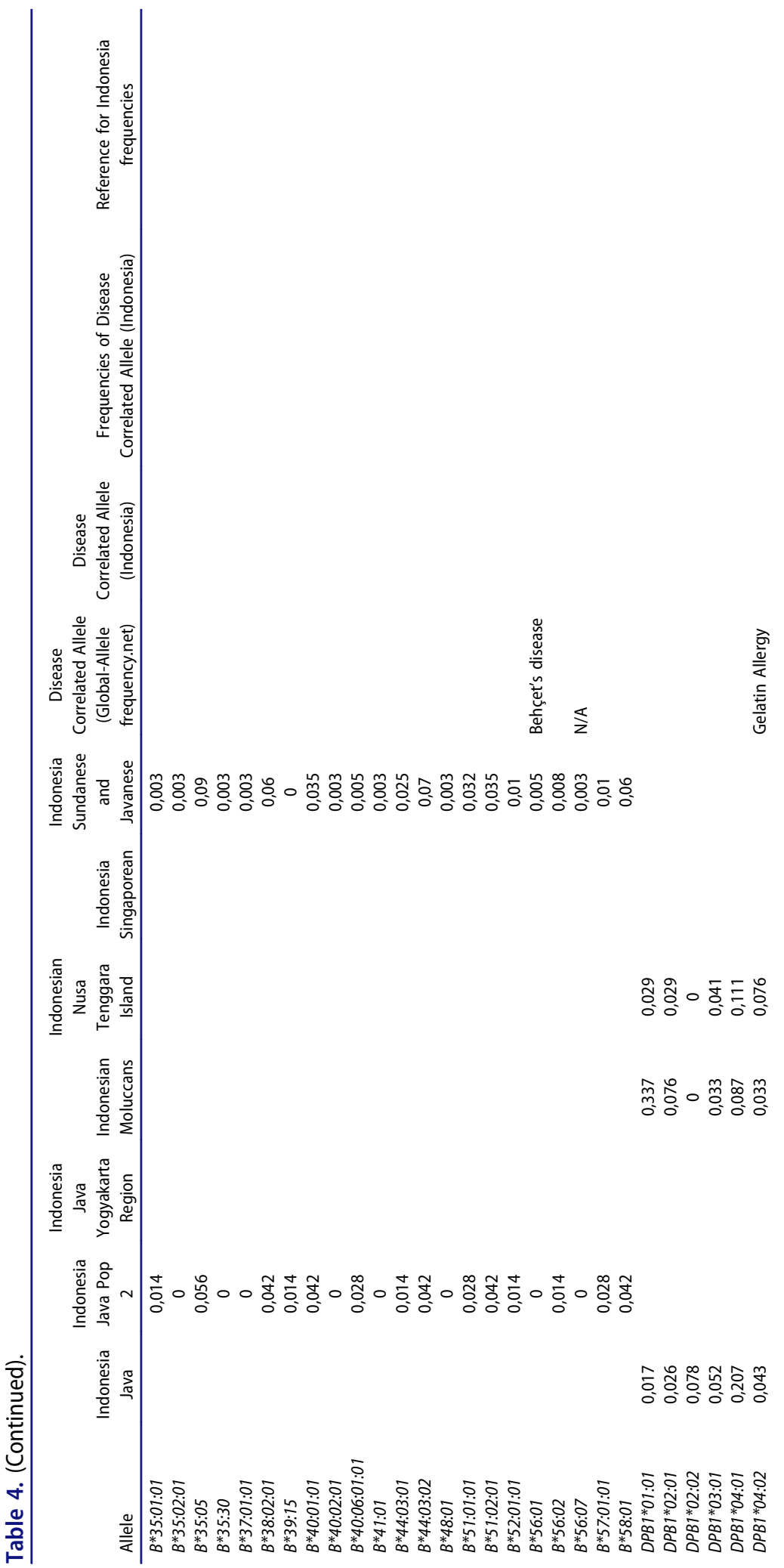




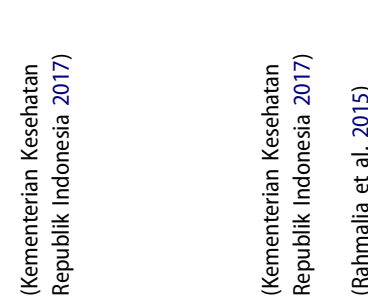

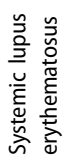
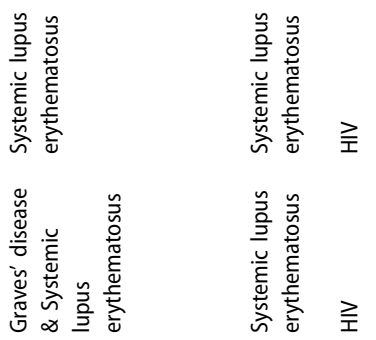

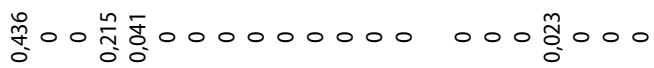

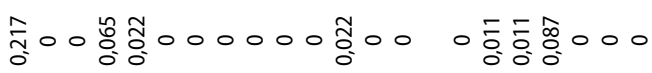

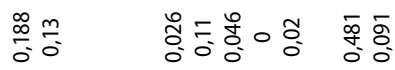

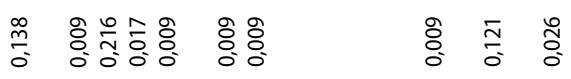




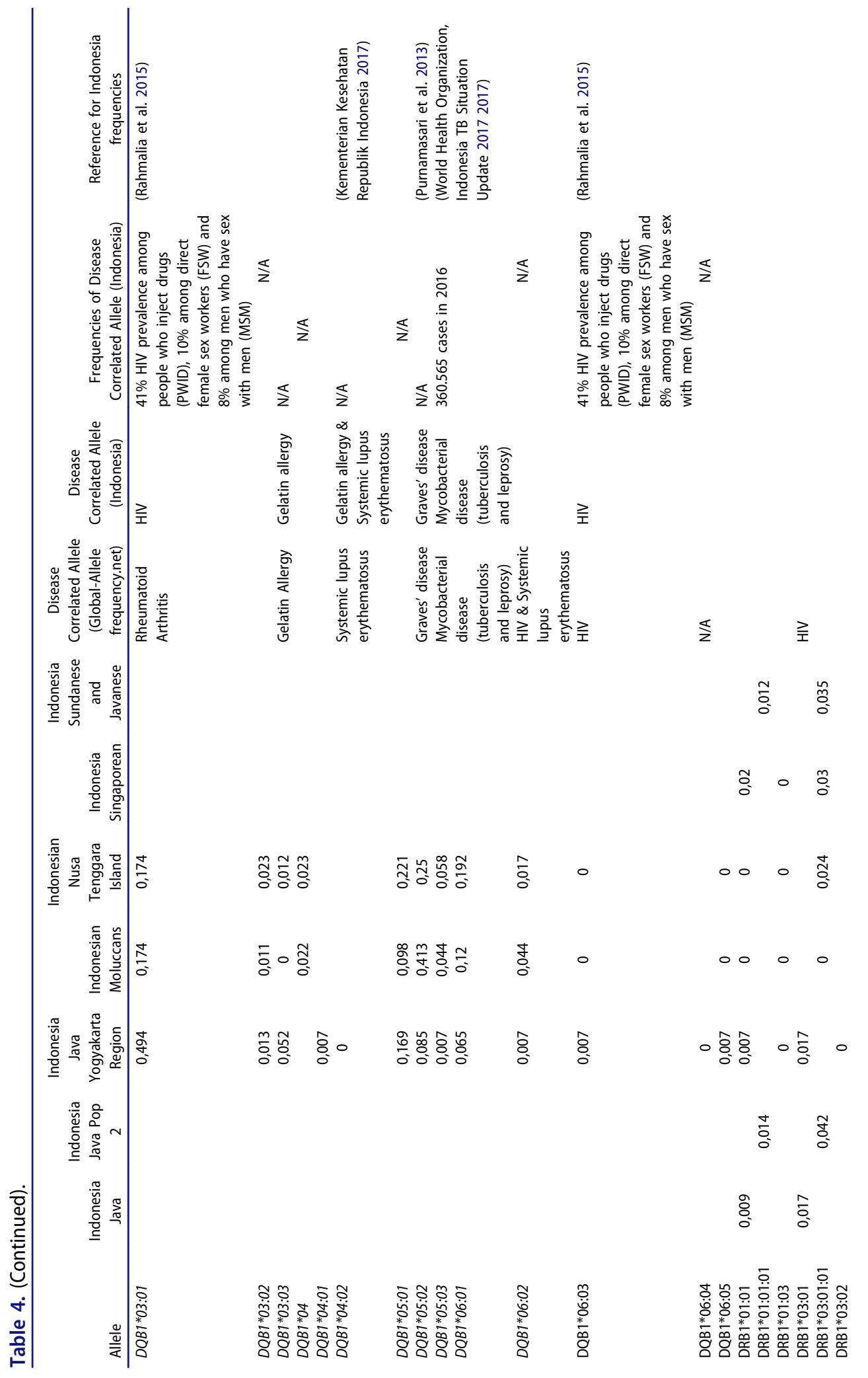



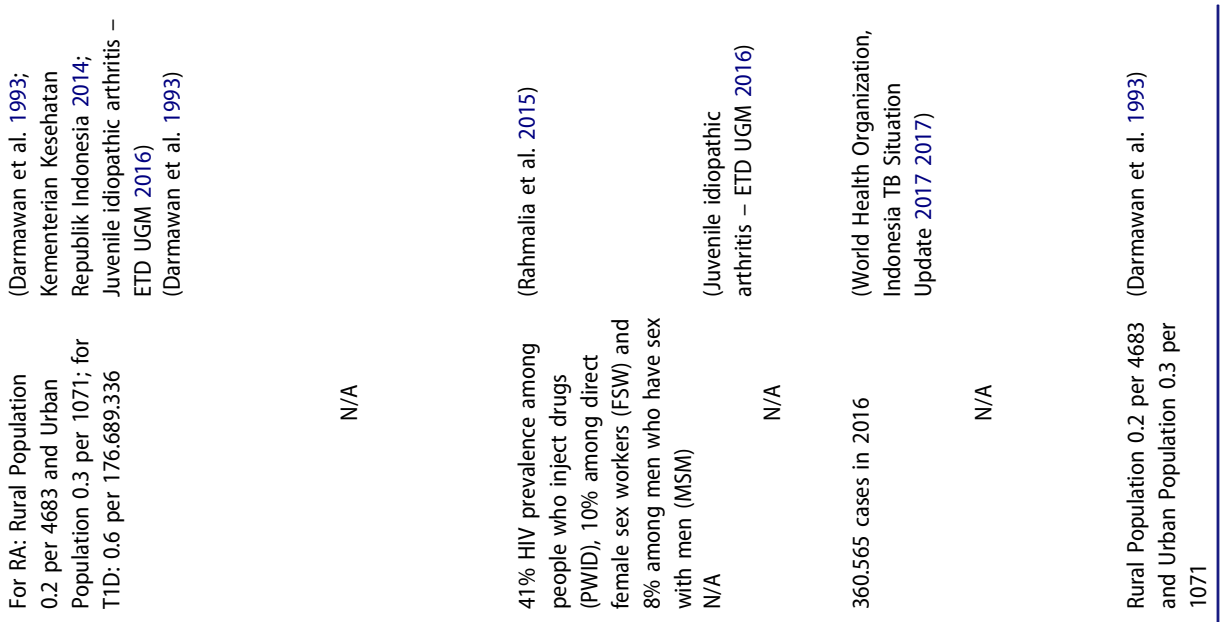

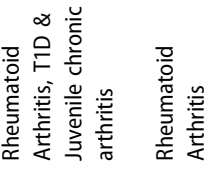

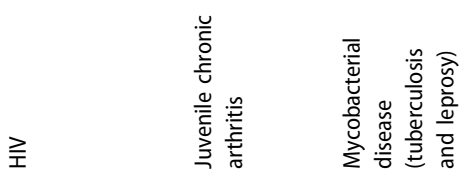

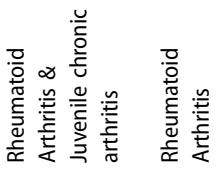
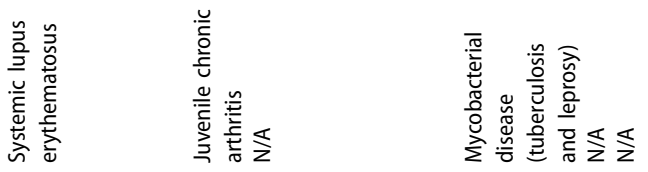

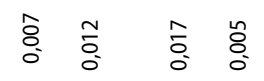

$\frac{\hat{m}}{\circ}$

:

ڤั)

$\circ$

$$
\text { : } 0: 0000
$$

:

- $\quad \bigsqcup_{0}^{\infty} 0 \frac{\infty}{0} 0000$

- $\quad \circ \frac{0}{0}$

- $\quad 00 \frac{0}{0} 000000$

管 $\quad 0 \overbrace{0}^{\infty}$

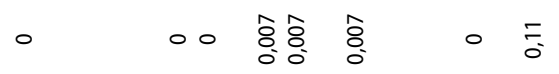

$$
00 \stackrel{0}{0}_{0}^{\circ}
$$

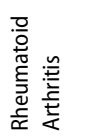




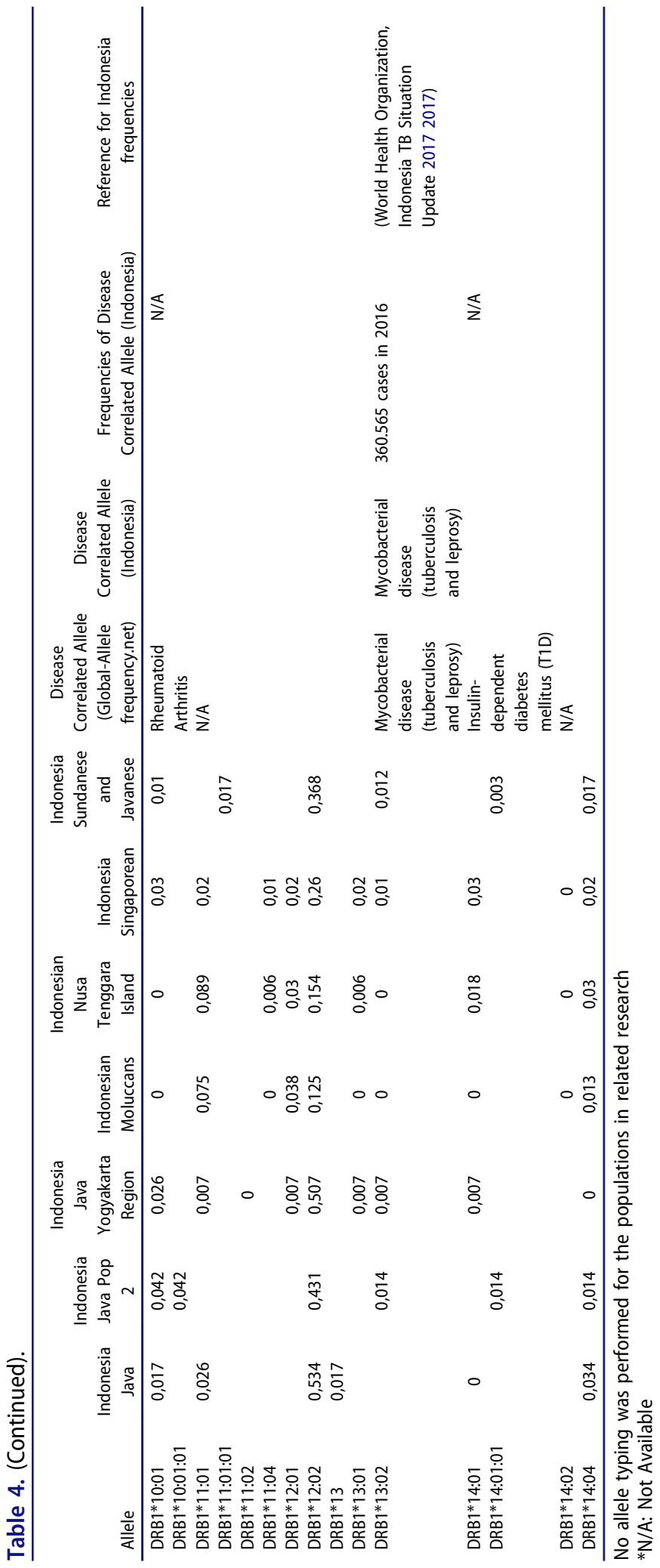


disease correlation research so there is a lot questions in this topic that needs to be answered in the future.

\section{Declaration of Interest}

The authors declare that there is no conflict of interest.

\section{ORCID}

Krisnawan Andy Pradana (1) http://orcid.org/0000-0002-1087-1200

Mariana Wahjudi (i) http://orcid.org/0000-0002-5861-2566

\section{References}

Achord AP, Lewis RE, Brackin MN, Henderson H, Cruse JM. 1996. HIV-1 disease association with HLA-DQ antigens in African Americans and Caucasians. Pathobiology. 64:204-08.

Al Jabri AA. 2002. HLA and in vitro susceptibility to HIV infection. Mol Immunol. 38:959-67.

Amiel J. 1967. Study of leucocyte phenotypes in Hodgkins' disease. Histocompat Test. 1967:79-81. Anonim. 2019. The Allele Frequency Net Database - Allele, haplotype and genotype frequencies in Worldwide Populations. [accessed 2019 Jan 10]. Available from: http://www.allelefrequencies.net/

Armstrong KM, Piepenbrink KH, Baker BM. 2008. Conformational changes and flexibility in T-cell receptor recognition of peptide-MHC complexes. Biochem J [Internet]. [accessed 2018 Oct 28]. 415:183-96. doi:10.1042/BJ20080850

Ayed K, Gorgi Y, Ayed-Jendoubi S, Bardi R. 2004. The involvement of HLA -DRB1*, DQA1*, $\mathrm{DQB1}^{\star}$ and complement C4A loci in diagnosing systemic lupus erythematosus among Tunisians. Ann Saudi Med. 24:31-35.

Bentham J, Morris DL, Graham DSC, Pinder CL, Tombleson P, Behrens TW, Martín J, Fairfax BP, Knight JC, Chen L, et al. 2015. Genetic association analyses implicate aberrant regulation of innate and adaptive immunity genes in the pathogenesis of systemic lupus erythematosus. Nat Genet [Internet]. [accessed 2019 Aug 27]. 47:1457-64. Available from: http://europepmc.org/ abstract/MED/26502338

Bodd M, Kim C, Lundin KEA, Sollid LM. 2012. T-Cell response to gluten in patients with HLA-DQ2.2 reveals requirement of peptide-MHC stability in celiac disease. Gastroenterology [Internet]. [accessed 2018 Oct 28]. 142:552-61. Available from: http://linkinghub.elsevier.com/ retrieve/pii/S0016508511015824

Bothamley GH, Beck JS, Schreuder G, D’Amaro J, de Vries RRP, Kardjito T, Ivanyi J. 1989. Association of Tuberculosis and M. tuberculosis-specific antibody levels with HLA. J Infect Dis [Internet]. [accessed 2019 Aug 24]. 159:549-55. Available from: https://academic.oup.com/jid/ article-lookup/doi/10.1093/infdis/159.3.549

Bulek AM, Cole DK, Skowera A, Dolton G, Gras S, Madura F, Fuller A, Miles JJ, Gostick E, Price DA, et al. 2012. Structural basis for the killing of human beta cells by CD8+ T cells in type 1 diabetes. Nat Immunol [Internet]. [accessed 2018 Oct 28]. 13:283-89. Available from: http:// www.nature.com/articles/ni.2206

Carapito R, Radosavljevic M, Bahram S. 2016. Next-generation sequencing of the HLA locus: methods and impacts on HLA typing, population genetics and disease association studies. Hum Immunol [Internet]. [cited 2018 Oct 24]. 77:1016-23. Available from: https://linkinghub. elsevier.com/retrieve/pii/S019888591630043X

Chan SH, Lin YN, Wee GB, Koh WH, Boey ML. 1994. HLA class 2 genes in Singaporean Chinese rheumatoid arthritis. Rheumatology. 33:713-17.

Charron D, International Histocompatibility Workshop and Conference, editor. 1997. HLA: genetic diversity of HLA: functional and medical implication. In: Proceedings of the twelfth international 
histocompatibility workshop and conference. Vol. 2. Conference. Sèvres. France: EDK Med. and Scientific Internat. Publ., 273-296.

Chen B, Li J, He C, Li D, Tong W, Zou Y, Xu W. 2017. Role of HLA-B27 in the pathogenesis of ankylosing spondylitis. Mol Med Rep [Internet]. [cited 2019 Aug 25]. 15:1943-51. Available from: https://www.ncbi.nlm.nih.gov/pmc/articles/PMC5364987/

Cole DK, Bulek AM, Dolton G, Schauenberg AJ, Szomolay B, Rittase W, Trimby A, Jothikumar P, Fuller A, Skowera A, et al. 2016. Hotspot autoimmune T cell receptor binding underlies pathogen and insulin peptide cross-reactivity. J Clin Invest [Internet]. [cited 2018 Oct 28]. 126:2191-204. Available from: https://www.jci.org/articles/view/85679

Collins D, Hafidz F, Mustikawati D. 2017. The economic burden of tuberculosis in Indonesia. Int J Tuberc Lung Dis Off J Int Union Tuberc Lung Dis. 21:1041-48.

Cortes LM, Baltazar LM, Lopez-Cardona MG, Olivares N, Ramos C, Salazar M, Sandoval L, Lorenz MGO, Chakraborty R, Paterson AD, et al. 2004. HLA class II haplotypes in Mexican systemic lupus erythematosus patients. Hum Immunol. 65:1469-76.

Cutbush S, Chikanza IC, Biro PA, Bekker C, Stein M, Lutalo S, Garcia-Pacheco JM, McCloskey DS, Lanchbury JS, Sachs JA. 1993. Sequence-specific oligonucleotide typing in Shona patients with rheumatoid arthritis and healthy controls from Zimbabwe. Tissue Antigens. 41:169-72.

Dandekar S, Wijesuriya H, Geiger T, Hamm D, GW M, Owens GC. 2016. Shared HLA class I and II Alleles and Clonally restricted public and private brain-infiltrating $\alpha \beta \mathrm{T}$ cells in a cohort of rasmussen encephalitis surgery patients. Front Immunol [Internet]. [accessed 2019 Aug 26]. 7. Available from: http://journal.frontiersin.org/article/10.3389/fimmu.2016.00608/full

Darmawan J, Muirden KD, Valkenburg HA, Wigley RD. 1993. The epidemiology of rheumatoid arthritis in Indonesia. Rheumatology. 32:537-40.

de Juan MD, Reta A, Cancio J, Belzunegui J, Cuadrado E. 1999. HLA-A*9, a probable secondary susceptibility marker to ankylosing spondylitis in Basque patients. Tissue Antigens. 53:161-66.

Dendrou CA, Petersen J, Rossjohn J, Fugger L. 2018. HLA variation and disease. Nat Rev Immunol [Internet]. [accessed 2018 Oct 24]. 18:325-39. Available from: https://www.nature.com/articles/ nri.2017.143

Dharmana E, Joosten I, Tijssen HJ, Gasem MH, Indarwidayati R, Keuter M, Dolmans WMV, Van der Meer JWM. 2002. HLA-DRB1 ${ }^{\star} 12$ is associated with protection against complicated typhoid fever, independent of tumour necrosis factor alpha. Eur J Immunogenet. 29:297-300.

Ding J, Wang Y, Cheng T, Chen X, Gao B. 2010. Identification of HLA-A24-binding peptides of mycobacterium tuberculosis derived proteins with beta $2 \mathrm{~m}$ linked HLA-A24 single chain expressing cells. Immunol Invest [Internet]. [accessed 2019 Aug 25]. 39:103-13. doi:10.3109/ 08820130903496777

Dubois PC, Trynka G, Franke L, Hunt KA, Romanos J, Curtotti A, Zhernakova A, Heap GA, Adány R, Aromaa A, et al. 2010. Multiple common variants for celiac disease influencing immune gene expression. Nat Genet [Internet]. [accessed 2019 Aug 27]. 42:295-302. Available from: http://europepmc.org/abstract/MED/20190752

Eberl M, Engel R, Aberle S, Fisch P, Jomaa H, Pircher H. 2005. Human V $\gamma 9 / \mathrm{V} \delta 2$ effector memory T cells express the killer cell lectin-like receptor G1 (KLRG1). J Leukoc Biol [Internet]. [accessed 2018 Oct 28]. 77:67-70. doi:10.1189/jlb.0204096

Elfishawi MM, Elgengehy F, Mossallam G, Elfishawi S, Alfishawy M, Gad A, Mokhtar I. 2019. HLA class I in Egyptian patients with Behçet's disease: new association with susceptibility, protection, presentation and severity of manifestations. Immunol Invest [Internet]. [accessed 2019 Aug 25]. 48:121-29. doi:10.1080/08820139.2018.1517364

Erlich H. 2012. HLA DNA typing: past, present, and future. Tissue Antigens [Internet]. [accessed 2018 Oct 24]. 80:1-11. doi:10.1111/j.1399-0039.2012.01881.x

Fallang L-E, Bergseng E, Hotta K, Berg-Larsen A, Kim C-Y, Sollid LM. 2009. Differences in the risk of celiac disease associated with HLA-DQ2.5 or HLA-DQ2.2 are related to sustained gluten antigen presentation. Nat Immunol [Internet]. [accessed 2018 Oct 28]. 10:1096-101. Available from: http://www.nature.com/articles/ni.1780

Ferreira RC, Pan-Hammarström Q, Graham RR, Fontán G, Lee AT, Ortmann W, Wang N, Urcelay E, Fernández-Arquero M, Núñez C, et al. 2012. High-density SNP mapping of the 
HLA region identifies multiple independent susceptibility loci associated with selective IgA deficiency.Goldgar DE, editor. PLoS Genet [Internet]. [accessed 2018 Oct 28]. 8:e1002476. doi:10.1371/journal.pgen.1002476

Gao X, Matheson B. 1996. A novel HLA-A*24 $\left(\mathrm{A}^{\star} 2410\right)$ identified in a Javanese population. Tissue Antigens [Internet]. [accessed 2018 Oct 27]. 48:711-13. doi:10.1111/j.1399-0039.1996.tb02697.x

Gao X, Zimmet P, Serjeantson SW. 1992. HLA-DR,DQ sequence polymorphisms in Polynesians, Micronesians, and Javanese. Hum Immunol [Internet]. [accessed 2018 Oct 27]. 34:153-61. Available from: http://linkinghub.elsevier.com/retrieve/pii/019888599290107X

Gateva V, Sandling JK, Hom G, Taylor KE, Chung SA, Sun X, Ortmann W, Kosoy R, Ferreira RC, Nordmark G, et al. 2009. A large-scale replication study identifies TNIP1, PRDM1, JAZF1, UHRF1BP1 and IL10 as risk loci for systemic lupus erythematosus. Nat Genet [Internet]. [accessed 2019 Aug 27]. 41:1228-33. Available from: http://europepmc.org/abstract/MED/ 19838195

Ghodke Y, Joshi K, Chopra A, Patwardhan B. 2005. HLA and disease. Eur J Epidemiol [Internet]. [accessed 2019 Aug 21]. 20:475-88. doi:10.1007/s10654-005-5081-x

Goldfeld AE. 1998. Association of an HLA-DQ Allele with clinical tuberculosis. JAMA. 279:226.

Gönen S, Sari S, Kandur Y, Dalgiç B, Söylemezoğlu O. 2017. Evaluation of human leukocyte antigen class I and II antigens in helicobacter pylori-positive pediatric patients with active gastritis and duodenal ulcer. Arq Gastroenterol. 54:297-99.

Goris A, Pauwels I, Gustavsen MW, Van BS, Hilven K, Bos SD, Celius EG, Berg-Hansen P, Aarseth J, Myhr KM, et al. 2015. Genetic variants are major determinants of CSF antibody levels in multiple sclerosis. Brain J Neurol [Internet]. [accessed 2019 Aug 27]. 138:632-43. Available from: http://europepmc.org/abstract/MED/25616667

Goulder PJR, Walker BD. 2012. HIV and HLA class I: an evolving relationship. Immunity. 37:426-40.

Govind N, Choudhury A, Hodkinson B, Ickinger C, Frost J, Lee A, Gregersen PK, Reynolds RJ, Bridges JS, Hazelhurst S, et al. 2014. Immunochip identifies novel, and replicates known, genetic risk loci for rheumatoid arthritis in black South Africans. Mol Med Camb Mass [Internet]. [accessed 2019 Aug 27]. 20:341-49. Available from: http://europepmc.org/abstract/MED/ 25014791

Hahn M, Nicholson MJ, Pyrdol J, Wucherpfennig KW. 2005. Unconventional topology of self peptide-major histocompatibility complex binding by a human autoimmune $\mathrm{T}$ cell receptor. Nat Immunol [Internet]. [accessed 2018 Oct 28]. 6:490-96. Available from: http://www.nature.com/ articles/ni1187

Hajjej A, Almawi WY, Stayoussef M, Arnaiz-Villena A, Hattab L, Hmida S. 2019. Association of HLA-DRB1 and -DQB1 alleles with type 1 (autoimmune) diabetes in African Arabs: systematic review and meta-analysis. Immunol Invest [Internet]. [accessed 2019 Aug 25]. 48:130-46. doi:10.1080/08820139.2018.1493498

Hakonarson H, Grant SF, Bradfield JP, Marchand L, Kim CE, Glessner JT, Grabs R, Casalunovo T, Taback SP, Frackelton EC, et al. 2007. A genome-wide association study identifies KIAA0350 as a type 1 diabetes gene. Nature [Internet]. [accessed 2019 Aug 27]. 448:591-94. Available from: http://europepmc.org/abstract/MED/17632545

Han JW, Zheng HF, Cui Y, Sun LD, Ye DQ, Hu Z, Xu JH, Cai ZM, Huang W, Zhao GP, et al. 2009. Genome-wide association study in a Chinese Han population identifies nine new susceptibility loci for systemic lupus erythematosus. Nat Genet [Internet]. [accessed 2019 Aug 27]. 41:1234-37. Available from: http://europepmc.org/abstract/MED/19838193

Hani U. 2015. Correlation of single nucleotide polymorphism 35-Kb upstream of H LA -C and clinical profile of multidrug- resistant tuberculosis. J Clin Diagn Res [Internet]. [accessed 2019 Aug 26]. Available from: http://jcdr.net/article_fulltext.asp?issn=0973-709x\&year= 2015\&volume $=9$ \&issue $=9$ \&page $=$ DC10\&issn $=0973-709 x \& i d=6451$

Harkiolaki M, Holmes SL, Svendsen P, Gregersen JW, Jensen LT, McMahon R, Friese MA, van Boxel G, Etzensperger R, Tzartos JS, et al. 2009. T cell-mediated autoimmune disease due to low-affinity crossreactivity to common microbial peptides. Immunity [Internet]. [accessed 2018 
Oct 28]. 30:348-57. Available from: http://linkinghub.elsevier.com/retrieve/pii/ S1074761309001125

Harpini A 2018. Menuju Indonesia Bebas Filariasis. Kementeri Kesehat RI Kemenkes RI [Internet]. [accessed Oct 10]. Available from: http://www.depkes.go.id/download.php?file=download/pusda tin/infodatin/Infodatin-Filariasis-2016.pdf

Hollenbach JA, Thompson SD, Bugawan TL, Ryan M, Sudman M, Marion M, Langefeld CD, Thomson G, Erlich HA, Glass DN. 2010. Juvenile idiopathic arthritis and HLA class I and class II interactions and age-at-onset effects. Arthritis Rheum. 62:1781-91.

Hom G, Graham RR, Modrek B, Taylor KE, Ortmann W, Garnier S, Lee AT, Chung SA, Ferreira RC, Pant PV, et al. 2008. Association of systemic lupus erythematosus with C8orf13-BLK and ITGAM-ITGAX. N Engl J Med [Internet]. [accessed 2019 Aug 27]. 358:900-09. Available from: http://europepmc.org/abstract/MED/18204098

Hosomichi K, Shiina T, Tajima A, Inoue I. 2015. The impact of next-generation sequencing technologies on HLA research. J Hum Genet [Internet]. [accessed 2019 Aug 23]. 60:665-73. Available from: http://www.nature.com/articles/jhg2015102

Hovhannisyan Z, Weiss A, Martin A, Wiesner M, Tollefsen S, Yoshida K, Ciszewski C, Curran SA, Murray JA, David CS, et al. 2008. The role of HLA-DQ8 $\beta 57$ polymorphism in the anti-gluten T-cell response in coeliac disease. Nature [Internet]. [accessed 2018 Oct 28]. 456:534-38. Available from: http://www.nature.com/articles/nature07524

Howard PF, Hochberg MC, Bias WB, Arnett FC, McLean RH. 1986. Relationship between C4 null genes, HLA-D region antigens, and genetic susceptibility to systemic lupus erythematosus in Caucasian and black Americans. Am J Med. 81:187-93.

Hu X, Deutsch AJ, Lenz TL, Onengut-Gumuscu S, Han B, Chen W-M, Howson JMM, Todd JA, de Bakker PIW, Rich SS, et al. 2015. Additive and interaction effects at three amino acid positions in HLA-DQ and HLA-DR molecules drive type 1 diabetes risk. Nat Genet [Internet]. [accessed 2018 Oct 28]. 47:898-905. Available from: http://www.nature.com/articles/ng.3353

Hudjashov G, Karafet TM, Lawson DJ, Downey S, Savina O, Sudoyo H, Lansing JS, Hammer MF, Cox MP. 2017. Complex patterns of admixture across the Indonesian Archipelago. Mol Biol Evol. 34:2439-52.

Hüffmeier U, Uebe S, Ekici AB, Bowes J, Giardina E, Korendowych E, Juneblad K, Apel M, McManus R, Ho P, et al. 2010. Common variants at TRAF3IP2 are associated with susceptibility to psoriatic arthritis and psoriasis. Nat Genet [Internet]. [accessed 2019 Aug 27]. 42:996-99. Available from: http://europepmc.org/abstract/MED/20953186

Indonesia Population. 2019. Worldometers (2019). [accessed 2019 Jan 26]. Available from: http:// www.worldometers.info/world-population/indonesia-population/

Itoh Y, Inoko H, Kulski JK, Sasaki S, Meguro A, Takiyama N, Nishida T, Yuasa T, Ohno S, Mizuki N. 2006. Four-digit allele genotyping of the HLA-A and HLA-B genes in Japanese patients with Behcet's disease by a PCR-SSOP-Luminex method. Tissue Antigens. 67:390-94.

Jakkula E, Leppä V, Sulonen A-M, Varilo T, Kallio S, Kemppinen A, Purcell S, Koivisto K, Tienari P, Sumelahti M-L, et al. 2010. Genome-wide association study in a high-risk isolate for multiple sclerosis reveals associated variants in STAT3 gene. Am J Hum Genet [Internet]. [accessed 2019 Aug 27]. 86:285-91. Available from: https://www.ncbi.nlm.nih.gov/pmc/articles/ PMC2820168/

Jiang X, Källberg H, Chen Z, Ärlestig L, Rantapää-Dahlqvist S, Davila S, Klareskog L, Padyukov L, Alfredsson L. 2016. An Immunochip-based interaction study of contrasting interaction effects with smoking in ACPA-positive versus ACPA-negative rheumatoid arthritis. Rheumatol Oxf Engl [Internet]. [accessed 2019 Aug 27]. 55:149-55. Available from: http://europepmc.org/ abstract/MED/26272072

Jostins L, Ripke S, Weersma RK, Duerr RH, McGovern DP, Hui KY, Lee JC, Schumm LP, Sharma Y, Anderson CA, et al. 2012. Host-microbe interactions have shaped the genetic architecture of inflammatory bowel disease. Nature [Internet]. [accessed 2019 Aug 27]. 491:119-24. Available from: http://europepmc.org/abstract/MED/23128233

Jung ES, Cheon JH, Lee JH, Park SJ, Jang HW, Chung SH, Park MH, Kim TG, Oh HB, Yang SK, et al. 2016. HLA-C*01 is a risk factor for Crohn's disease. Inflamm Bowel Dis [Internet]. 
[accessed 2019 Aug 27]. 22:796-806. Available from: http://europepmc.org/abstract/MED/ 26891255

Juvenile idiopathic arthritis - ETD UGM. 2016. [place unknown].

Kakuta Y, Kawai Y, Naito T, Hirano A, Umeno J, Fuyuno Y, Liu Z, Li D, Nakano T, Izumiyama Y, et al. 2019. A genome-wide association study identifying RAP1A as a novel susceptibility gene for Crohn's disease in Japanese individuals. J Crohns Colitis [Internet]. [accessed 2019 Aug 27]. 13:648-58. Available from: http://europepmc.org/abstract/MED/30500874

Kankonkar S, Shankarkumar U. 2008. HLA DRB Alleles in chronic hepatitis B infected patients. Int J Hum Genet [Internet]. [accessed 2019 Aug 25]. 8:331-34. doi:10.1080/ 09723757.2008.11886048

Kementerian Kesehatan Republik Indonesia. 2014. Situasi dan Analisis diabetes. Jakarta: Kementerian Kesehatan Republik Indonesia.

Kementerian Kesehatan Republik Indonesia. 2017. Situasi Lupus di Indonesia [Internet]. [accessed 2018 Oct 31]. Available from: http://www.depkes.go.id/resources/download/pusdatin/infodatin/ Infodatin-Lupus-2017.pdf

Kho S, Marfurt J, Noviyanti R, Kusuma A, Piera KA, Burdam FH, Kenangalem E, Lampah DA, Engwerda CR, Poespoprodjo JR, et al. 2015. Preserved dendritic cell HLA-DR expression and reduced regulatory $\mathrm{T}$ cell activation in asymptomatic plasmodium falciparum and $\mathrm{P}$. vivax infection. Adams JH, editor. Infect Immun. 83:3224-32.

Khor AH-P, Lim K-S, Tan C-T, Kwan Z, Tan W-C, Wu DB-C, Ng -C-C. 2017. HLA-A*31: 01 and HLA-B $^{\star}$ 15:02 association with Stevens-Johnson syndrome and toxic epidermal necrolysis to carbamazepine in a multiethnic Malaysian population. Pharmacogenet Genomics. 27:275-78.

Kishore A, Petrek M. 2018. Next-generation sequencing based HLA typing: deciphering immunogenetic aspects of sarcoidosis. Front Genet [Internet]. [accessed 2019 Apr 1]. 9. Available from: https://www.ncbi.nlm.nih.gov/pmc/articles/PMC6210504/

Klemp P, Du Toit ED, Issacs S, Mody GM, Oudshoorn M. 1988. HLA-A,B,C, and DR antigens, GLO I and Bf marker profiles in 75 Cape coloured patients with systemic lupus erythematosus (SLE). Tissue Antigens. 32:12-16.

Koning F, Thomas R, Rossjohn J, Toes RE. 2015. Coeliac disease and rheumatoid arthritis: similar mechanisms, different antigens. Nat Rev Rheumatol [Internet]. [accessed 2018 Oct 28]. 11:450-61. Available from: http://www.nature.com/articles/nrrheum.2015.59

Koo J-W, Oh SH, Chang SO, Park MH, Lim MJ, Yoo T-J, Kim CS. 2003. Association of HLA-DR and type II collagen autoimmunity with Meniere's disease. Tissue Antigens. 61:99-103.

Krause-Kyora B, Nutsua M, Boehme L, Pierini F, Pedersen DD, Kornell S-C, Drichel D, Bonazzi M, Möbus L, Tarp P, et al. 2018. Ancient DNA study reveals HLA susceptibility locus for leprosy in medieval Europeans. Nat Commun [Internet]. [accessed 2019 Aug 25]. 9:1-11. Available from: https://www.nature.com/articles/s41467-018-03857-x

Lang HLE, Jacobsen H, Ikemizu S, Andersson C, Harlos K, Madsen L, Hjorth P, Sondergaard L, Svejgaard A, Wucherpfennig K, et al. 2002. A functional and structural basis for TCR cross-reactivity in multiple sclerosis. Nat Immunol [Internet]. [accessed 2018 Oct 28]. 3:940-43. Available from: http://www.nature.com/articles/ni835

Laufer VA, Tiwari HK, Reynolds RJ, Danila MI, Wang J, Edberg JC, Kimberly RP, Kottyan LC, Harley JB, Mikuls TR, et al. 2019. Genetic influences on susceptibility to rheumatoid arthritis in African-Americans. Hum Mol Genet [Internet]. [accessed 2019 Aug 27]. 28:858-74. Available from: http://europepmc.org/abstract/MED/30423114

Liu JZ, Van SS, Huang H, Ng SC, Alberts R, Takahashi A, Ripke S, Lee JC, Jostins L, Shah T, et al. 2015. Association analyses identify 38 susceptibility loci for inflammatory bowel disease and highlight shared genetic risk across populations. Nat Genet [Internet]. [accessed 2019 Aug 27]. 47:979-86. Available from: http://europepmc.org/abstract/MED/26192919

Lombard Z, Brune AE, Hoal EG, Babb C, Van Helden PD, Epplen JT, Bornman L. 2006. HLA class II disease associations in southern Africa. Tissue Antigens. 67:97-110.

Mack SJ, Bugawan TL, Moonsamy PV, Erlich JA, Trachtenberg EA, Paik YK, Begovich AB, Saha N, Beck HP, Stoneking M, et al. 2000. Evolution of Pacific/Asian populations inferred from HLA 
class II allele frequency distributions. Tissue Antigens [Internet]. [accessed 2018 Oct 27]. 55:383-400. doi:10.1034/j.1399-0039.2000.550501.x

Madsen LS, Andersson EC, Jansson L, Krogsgaard M, Andersen CB, Engberg J, Strominger JL, Svejgaard A, Hjorth JP, Holmdahl R, et al. 1999. A humanized model for multiple sclerosis using HLA-DR2 and a human T-cell receptor. Nat Genet [Internet]. [accessed 2018 Oct 28]. 23:343-347. Available from: http://www.nature.com/articles/ng1199_343

Maira D, Vansan A, Maria A, Laguila Visentainer JE, de Souz CA. 2014. HLA and infectious diseases. In: Xi Y, editor. HLA assoc important dis [Internet]. London: InTech. [accessed 2019 Aug 26]. Available from: http://www.intechopen.com/books/hla-and-associated-importantdiseases/hla-and-infectious-diseases

Manandhar T, Kunze-Schumacher H, Huyton T, Celik AA, Blasczyk R, Bade-Doeding C. 2016. Understanding the obstacle of incompatibility at residue 156 within HLA-B ${ }^{\star} 35$ subtypes. Immunogenetics [Internet]. [accessed 2018 Oct 27]. 68:247-60. doi:10.1007/s00251-0150896-4

Mannering SI, Harrison LC, Williamson NA, Morris JS, Thearle DJ, Jensen KP, Kay TWH, Rossjohn J, Falk BA, Nepom GT, et al. 2005. The insulin A-chain epitope recognized by human $\mathrm{T}$ cells is posttranslationally modified. J Exp Med [Internet]. [accessed 2018 Oct 28]. 202:1191-97. doi:10.1084/jem.20051251

Mardian Y, Yano Y, Wasityastuti W, Ratnasari N, Liang Y, Putri WA, Triyono T, Hayashi Y. 2017. Genetic polymorphisms of HLA-DP and isolated anti-HBc are important subsets of occult hepatitis B infection in Indonesian blood donors: a case-control study. Virol J [Internet]. [accessed 2019 Aug 24]. 14:201. doi:10.1186/s12985-017-0865-7

Mardjuadi A 1999. HLA-B27 associated rheumatologic diseases in Indonesia [Internet]. [accessed 2019 Aug 24]. Available from: https://dare.uva.nl/search?identifier=4826c54e-0a41-4a40-befe $-5953 \mathrm{c} 380 \mathrm{ed} 3 \mathrm{~d}$

Martell RW, Du Toit ED, Kalla AA, Meyers OL. 1989. Association of rheumatoid arthritis with HLA in three South African populations-whites, blacks and a population of mixed ancestry. South Afr Med J Suid-Afr Tydskr Vir Geneeskd. 76:189-90.

Matei HV, Vica ML, Siserman CV. 2018. Association between HLA class II alleles and hepatitis $\mathrm{B}$ virus infection in Transylvania, Romania. Immunol Invest [Internet]. [accessed 2019 Aug 25]. 47:735-44. doi:10.1080/08820139.2018.1489832

Meyer D,C, Aguiar VR, Bitarello BD, Brandt DY, Nunes K. 2018. A genomic perspective on HLA evolution. Immunogenetics [Internet]. [accessed 2018 Oct 24]. 70:5-27. doi:10.1007/s00251-0171017-3

Mignot E, Lin L, Rogers W, Honda Y, Qiu X, Lin X, Okun M, Hohjoh H, Miki T, Hsu SH, et al. 2001. Complex HLA-DR and -DQ interactions confer risk of narcolepsy-cataplexy in three ethnic groups. Am J Hum Genet [Internet]. [accessed 2018 Oct 28]. 68:686-99. Available from: http:// linkinghub.elsevier.com/retrieve/pii/S0002929707631085

Miyadera H, Ohashi J, Lernmark $\AA$, Kitamura T, Tokunaga K. 2015. Cell-surface MHC density profiling reveals instability of autoimmunity-associated HLA. J Clin Invest [Internet]. [accessed 2018 Oct 28]. 125:275-91. Available from: http://www.jci.org/articles/view/74961

Mizuki N, Ota M, Katsuyama Y, Yabuki K, Ando H, Shiina T, Nomura E, Onari K, Ohno S, Inoko H. 2001a. HLA-B ${ }^{\star} 51$ allele analysis by the PCR-SBT method and a strong association of HLA-B ${ }^{\star} 5101$ with Japanese patients with Behcet's disease. Tissue Antigens. 58:181-84.

Mizuki N, Ota M, Katsuyama Y, Yabuki K, Ando H, Shiina T, Palimeris GD, Kaklamani E, Ito D, Ohno S, et al. 2002a. Sequencing-based typing of HLA-B ${ }^{\star} 51$ alleles and the significant association of HLA-B ${ }^{\star} 5101$ and $-B^{\star} 5108$ with Behcet's disease in Greek patients. Tissue Antigens. 59:118-21.

Mizuki N, Ota M, Katsuyama Y, Yabuki K, Ando H, Yoshida M, Onari K, Nikbin B, Davatchi F, Chams $\mathrm{H}$, et al. 2001b. HLA class I genotyping including HLA-B ${ }^{\star} 51$ allele typing in the Iranian patients with Behcet's disease. Tissue Antigens. 57:457-62.

Mizuki N, Yabuki K, Ota M, Katsuyama Y, Ando H, Nomura E, Funakoshi K, Davatchi F, Chams H, Nikbin B, et al. 2002b. Analysis of microsatellite polymorphism around the HLA-B locus in Iranian patients with Behcet's disease. Tissue Antigens. 60:396-99. 
Molberg Ø, Mcadam SN, Körner R, Quarsten H, Kristiansen C, Madsen L, Fugger L, Scott H, Norén O, Roepstorff P, et al. 1998. Tissue transglutaminase selectively modifies gliadin peptides that are recognized by gut-derived T cells in celiac disease. Nat Med [Internet]. [accessed 2018 Oct 28]. 4:713-17. Available from: http://www.nature.com/doifinder/10.1038/nm0698-713

Murphy K. 2014. Janeway's immunobiology. New York: Garland Science.

Nagy M, Entz P, Otremba P, Schoenemann C, Murphy N, Dapprich J. 2007. Haplotype-specific extraction: a universal method to resolve ambiguous genotypes and detect new alleles? demonstrated on HLA-B. Tissue Antigens [Internet]. [accessed 2018 Oct 26]. 69:176-80. doi:10.1111/ j.1399-0039.2006.00741.x

Nasution AR, Mardjuadi A, Kunmartini S, Suryadhana NG, Setyohadi B, Sudarsono D, Lardy NM, Feltkamp TE. 1997. HLA-B27 subtypes positively and negatively associated with spondyloarthropathy. J Rheumatol. 24:1111-14.

Negi S, Juyal G, Senapati S, Prasad P, Gupta A, Singh S, Kashyap S, Kumar A, Kumar U, Gupta R, et al. 2013. A genome-wide association study reveals ARL15, a novel non-HLA susceptibility gene for rheumatoid arthritis in North Indians. Arthritis Rheum [Internet]. [accessed 2019 Aug 27]. 65:3026-35. Available from: http://europepmc.org/abstract/MED/23918589

Nelson JL, Boyer G, Templin D, Lanier A, Barrington R, Nisperos B, Smith A, Mickelson E, Hansen JA. 1992. HLA antigens in Tlingit Indians with rheumatoid arthritis. Tissue Antigens. 40:57-63.

O'hUigin C, Kulkarni S, Xu Y, Deng Z, Kidd J, Kidd K, Gao X, Carrington M. 2011. The molecular origin and consequences of escape from miRNA regulation by HLA-C Alleles. Am J Hum Genet [Internet]. [accessed 2018 Oct 28]. 89:424-31. Available from: http://linkinghub.elsevier.com/ retrieve/pii/S0002929711003211

Okada Y, Yamazaki K, Umeno J, Takahashi A, Kumasaka N, Ashikawa K, Aoi T, Takazoe M, Matsui T, Hirano A, et al. 2011. HLA-Cw $1202-\mathrm{B}^{\star} 5201-\mathrm{DRB1}{ }^{\star} 1502$ haplotype increases risk for ulcerative colitis but reduces risk for Crohn's disease. Gastroenterology [Internet]. [accessed 2019 Aug 27]. 141:864-871.e1-5. Available from: http://europepmc.org/abstract/MED/21699788

Ooi JD, Petersen J, Tan YH, Huynh M, Willett ZJ, Ramarathinam SH, Eggenhuizen PJ, Loh KL, Watson KA, Gan PY, et al. 2017. Dominant protection from HLA-linked autoimmunity by antigen-specific regulatory $T$ cells. Nature [Internet]. [accessed 2018 Oct 28]. 545:243-47. Available from: http://www.nature.com/doifinder/10.1038/nature22329

Ouni N, Chaaben AB, Kablouti G, Ayari F, Douik H, Abaza H, Gara S, Elgaaied-Benammar A, Guemira F, Tamouza R. 2019. The impact of HLA-G 3'UTR polymorphisms in breast cancer in a Tunisian population. Immunol Invest [Internet]. [accessed 2019 Aug 25]. 48:521-32. doi:10.1080/08820139.2019.1569043

Padyukov L, Seielstad M, Ong RT, Ding B, Rönnelid J, Seddighzadeh M, Alfredsson L, Klareskog L. 2011. A genome-wide association study suggests contrasting associations in ACPA-positive versus ACPA-negative rheumatoid arthritis. Ann Rheum Dis [Internet]. [accessed 2019 Aug 27]. 70:259-65. Available from: http://europepmc.org/abstract/MED/21156761

Park MH, Song EY, Park HJ, Kwon SY, Han SK, Shim YS. 2002. HLA-DRB1 and DQB1 gene polymorphism is associated with multidrug-resistant tuberculosis in Korean patients. Hum Immunol. 63:S33.

Perwitasari D, Darmawan E, Mulyani U, Vlies PD, Alffenaar J-W, Atthobar J, Wilffert B. 2018. Polymorphisms of NAT2, CYP2E1, GST, and HLA related to drug-induced liver injury in indonesian tuberculosis patients. Int J Mycobacteriology. 7:380.

PMC E. 2007. Genome-wide association study of 14,000 cases of seven common diseases and 3,000 shared controls. Nature [Internet]. [accessed 2019 Aug 27]. 447:661-78. Available from: http:// europepmc.org/abstract/MED/17554300

Png E, Thalamuthu A, Ong RTH, Snippe H, Boland GJ, Seielstad M. 2011. A genome-wide association study of hepatitis B vaccine response in an Indonesian population reveals multiple independent risk variants in the HLA region. Hum Mol Genet [Internet]. [accessed 2019 Aug 24]. 20:3893-98. Available from: https://academic.oup.com/hmg/article-lookup/doi/10.1093/ $\mathrm{hmg} / \mathrm{ddr} 302$ 
Prasetyo AA, Dharmawan R, Raharjo I, Hudiyono. 2016. Human leukocyte antigen-E Alleles are associated with hepatitis $\mathrm{C}$ virus, torque teno virus, and toxoplasma co-infections but are not associated with hepatitis B Virus, hepatitis D virus, and GB virus C co-infections in human immunodeficiency virus patients. J Glob Infect Dis. 8:75-81.

Pugliese A, Zeller M, Fernandez A, Zalcberg LJ, Bartlett RJ, Ricordi C, Pietropaolo M, Eisenbarth GS, Bennett ST, Patel DD. 1997. The insulin gene is transcribed in the human thymus and transcription levels correlate with allelic variation at the INS VNTR-IDDM2 susceptibility locus for type 1 diabetes. Nat Genet [Internet]. [accessed 2018 Oct 28]. 15:293-97. Available from: http://www.nature.com/doifinder/10.1038/ng0397-293

Purnamasari D, Subekti I, Adam J, Tahapary D; Division of Endocrinology and Metabolism, Department of Internal Medicine, Faculty of Medicine University of Indonesia, Cipto Mangunkusumo Hospital, Jakarta, Indonesia. 2013. Indonesian clinical practice guidelines for the management of thyroid dysfunction during pregnancy. J ASEAN Fed Endocr Soc 28:18-20.

Quandt JA, Baig M, Yao K, Kawamura K, Huh J, Ludwin SK, Bian H-J, Bryant M, Quigley L, Nagy ZA, et al. 2004. Unique clinical and pathological features in HLA-DRB1 ${ }^{\star} 0401$-restricted MBP 111-129-specific humanized TCR transgenic mice. J Exp Med [Internet]. [accessed 2018 Oct 28]. 200:223-34. Available from: http://www.jem.org/lookup/doi/10.1084/jem.20030994

Quigley MF, Greenaway HY, Venturi V, Lindsay R, Quinn KM, Seder RA, Douek DC, Davenport MP, Price DA. 2010. Convergent recombination shapes the clonotypic landscape of the naive T-cell repertoire. Proc Natl Acad Sci [Internet]. [accessed 2018 Oct 27]. 107:19414-19. Available from: http://www.pnas.org/cgi/doi/10.1073/pnas.1010586107

Rahmalia A, Wisaksana R, Meijerink H, Indrati AR, Alisjahbana B, Roeleveld N, van der Ven AJAM, Laga M, van Crevel R. 2015. Women with HIV in Indonesia: are they bridging a concentrated epidemic to the wider community? BMC Res Notes [Internet]. [accessed 2018 Oct 31]. 8. Available from: http://www.biomedcentral.com/1756-0500/8/757

Raj P, Rai E, Song R, Khan S, Wakeland BE, Viswanathan K, Arana C, Liang C, Zhang B, Dozmorov I, et al. 2016. Regulatory polymorphisms modulate the expression of HLA class II molecules and promote autoimmunity. eLife [Internet]. [accessed 2018 Oct 28]. 5. Available from: https://elifesciences.org/articles/12089

Robinson J, Soormally AR, Hayhurst JD, Marsh SGE. 2016. The IPD-IMGT/HLA database - new developments in reporting HLA variation. Hum Immunol [Internet]. [accessed 2018 Oct 27]. 77:233-37. Available from: https://inkinghub.elsevier.com/retrieve/pii/S019888591600029X

Rompel R, Weidner W, Mueller-Eckhardt G. 1991. HLA association of idiopathic Peyronie's disease: an indication of autoimmune phenomena in etiopathogenesis? Tissue Antigens. 38:104-06.

Roshandel D, Gubitosi-Klug R, Bull SB, Canty AJ, Pezzolesi MG, King GL, Keenan HA, SnellBergeon JK, Maahs DM, Klein R, et al. 2018. Meta-genome-wide association studies identify a locus on chromosome 1 and multiple variants in the MHC region for serum C-peptide in type 1 diabetes. Diabetologia [Internet]. [accessed 2019 Aug 27]. 61:1098-1111. Available from: http:// europepmc.org/abstract/MED/29404672

Rudwaleit M, Tikly M, Gibson K, Pile K, Wordsworth P. 1995. HLA class II antigens associated with systemic lupus erythematosus in black South Africans. Ann Rheum Dis. 54:678-80.

Sakaguchi M, Nakayama T, Kaku H, Taniguchi K, Saito S, Kimura A, Inouye S. 2002. Analysis of HLA in children with gelatin allergy. Tissue Antigens. 59:412-16.

Sanchez-Mazas A, Poloni ES, Jacques G, Sagart L. 2005. HLA genetic diversity and linguistic variation in East Asia [Internet]. [accessed 2019 Aug 21]: 273-96. Available from: https://archiveouverte.unige.ch/unige: 13261

Scally SW, Petersen J, Law SC, Dudek NL, Nel HJ, Loh KL, Wijeyewickrema LC, Eckle SBG, van Heemst J, Pike RN, et al. 2013. . A molecular basis for the association of the HLA-DRB1 locus, citrullination, and rheumatoid arthritis. J Exp Med [Internet]. [accessed 2018 Oct 28]. 210:2569-82. Available from: http://www.jem.org/lookup/doi/10.1084/jem.20131241

Sethi DK, Schubert DA, Anders A-K, Heroux A, Bonsor DA, Thomas CP, Sundberg EJ, Pyrdol J, Wucherpfennig KW. 2011. A highly tilted binding mode by a self-reactive T cell receptor results 
in altered engagement of peptide and MHC. J Exp Med [Internet]. [accessed 2018 Oct 28]. 208:91-102. Available from: http://www.jem.org/lookup/doi/10.1084/jem.20100725

Smith WM. 2013. Gender and spondyloarthropathy-associated uveitis. J Ophthalmol [Internet]. [accessed 2019 Aug 25]. Available from: https://www.hindawi.com/journals/joph/2013/928264/

Soebono H, Giphart MJ, Schreuder GM, Klatser PR, de Vries RR. 1997. Associations between HLA-DRB1 alleles and leprosy in an Indonesian population. Int J Lepr Mycobact Dis Off Organ Int Lepr Assoc. 65:190-96.

Song S, Han M, Zhang H, Wang Y, Jiang H. 2013. Full screening and accurate subtyping of HLA$\mathrm{A}^{\star} 02$ alleles through group-specific amplification and mono-allelic sequencing. Cell $\mathrm{Mol}$ Immunol. 10:490-96.

Stadinski BD, Zhang L, Crawford F, Marrack P, Eisenbarth GS, Kappler JW. 2010. Diabetogenic $\mathrm{T}$ cells recognize insulin bound to IAg7 in an unexpected, weakly binding register. Proc Natl Acad Sci [Internet]. [accessed 2018 Oct 28]. 107:10978-83. Available from: http://www.pnas.org/ cgi/doi/10.1073/pnas.1006545107

Stuart PE, Nair RP, Tsoi LC, Tejasvi T, Das S, Kang HM, Ellinghaus E, Chandran V, CallisDuffin K, Ike R, et al. 2015. Genome-wide association analysis of psoriatic arthritis and cutaneous psoriasis reveals differences in their genetic architecture. Am J Hum Genet [Internet]. [accessed 2019 Aug 27]. 97:816-36. Available from: http://europepmc.org/ abstract/MED/26626624

Van DH, Franke L, Hunt KA, Gwilliam R, Zhernakova A, Inouye M, Wapenaar MC, Barnardo MC, Bethel G, Holmes GK, et al. 2007. A genome-wide association study for celiac disease identifies risk variants in the region harboring IL2 and IL21. Nat Genet [Internet]. [accessed 2019 Aug 27]. 39:827-29. Available from: http://europepmc.org/abstract/MED/17558408

Wasityastuti W, Yano Y, Ratnasari N, Triyono T, Triwikatmani C, Indrarti F, Heriyanto DS, Yamani LN, Liang Y, Utsumi T, et al. 2016. Protective effects of HLA-DPA1/DPB1 variants against Hepatitis B virus infection in an Indonesian population. Infect Genet Evol [Internet]. [accessed 2019 Aug 24]. 41:177-84. Available from: https://linkinghub.elsevier.com/retrieve/pii/ S1567134816301228

Weetman AP, Zhang L, Tandon N, Edwards OM. 1991. HLA associations with autoimmune Addison's disease. Tissue Antigens. 38:31-33.

Wei WH, Viatte S, Merriman TR, Barton A, Worthington J. 2017. Genotypic variability based association identifies novel non-additive loci DHCR7 and IRF4 in sero-negative rheumatoid arthritis. Sci Rep [Internet]. [accessed 2019 Aug 27]. 7:5261-5261. Available from: http://eur opepmc.org/abstract/MED/28706201

Weinstock C, Matheis N, Barkia S, Haager M-C, Janson A, Marković A, Bux J, Kahaly GJ. 2011. Autoimmune polyglandular syndrome type 2 shows the same HLA class II pattern as type 1 diabetes†. Tissue Antigens [Internet]. [accessed 2018 Oct 28]. 77:317-24. doi:10.1111/j.13990039.2011.01634.x

Williams RC, Hanson RL, Pettitt DJ, Sievers ML, Nelson RG, Knowler WC. 1996. HLA^A2 confers mortality risk for cardiovascular disease in Pimans. Tissue Antigens. 47:188-93.

Wongsurawat T, Nakkuntod J, Charoenwongse P, Snabboon T, Sridama V, Hirankarn N. 2006. The association between HLA class II haplotype with Graves' disease in Thai population. Tissue Antigens. 67:79-83.

World Health Organization, Indonesia TB Situation Update 2017. 2017. SEARO [Internet]. [accessed 2018 Oct 31]. Available from: http://www.searo.who.int/indonesia/topics/tb/ IndonesiaTBSituation2017/en/

Wucherpfennig KW, Strominger JL. 1995. Molecular mimicry in T cell-mediated autoimmunity: viral peptides activate human $\mathrm{T}$ cell clones specific for myelin basic protein. Cell [Internet]. [accessed 2018 Oct 28]. 80:695-705. Available from: http://linkinghub.elsevier.com/retrieve/pii/ 0092867495903488

Yabuki K, Ohno S, Mizuki N, Ando H, Tabbara KF, Goto K, Nomura E, Nakamura S, Ito N, Ota M, et al. 1999. HLA class I and II typing of the patients with Behcet's disease in Saudi Arabia. Tissue Antigens. 54:273-77. 
Yang J, Chow I-T, Sosinowski T, Torres-Chinn N, Greenbaum CJ, James EA, Kappler JW, Davidson HW, Kwok WW. 2014a. Autoreactive T cells specific for insulin B:11-23 recognize a low-affinity peptide register in human subjects with autoimmune diabetes. Proc Natl Acad Sci [Internet]. [accessed 2018 Oct 28]. 111:14840-45. Available from: http://www.pnas.org/cgi/doi/ $10.1073 /$ pnas.1416864111

Yang SK, Hong M, Zhao W, Jung Y, Baek J, Tayebi N, Kim KM, Ye BD, Kim KJ, Park SH, et al. 2014b. Genome-wide association study of Crohn's disease in Koreans revealed three new susceptibility loci and common attributes of genetic susceptibility across ethnic populations. Gut [Internet]. [accessed 2019 Aug 27]. 63:80-87. Available from: http://europepmc.org/abstract/ MED/23850713

Yano Y. 2015. Hepatitis B virus infection in Indonesia. World J Gastroenterol [Internet]. [accessed 2019 Aug 24]. 21:10714. Available from: http://www.wjgnet.com/1007-9327/full/v21/i38/10714. htm

Yazdanbakhsh M, Abadi K, De Roo M, Van Wouwe L, Denham D, Medeiros F, Verduijn W, GMThSRSM G, De Vries RRP. 1997. HLA and elephantiasis revisited. Eur J Immunogenet [Internet]. [accessed 2019 Aug 24]. 24:439-42. doi:10.1046/j.1365-2370.1997.d01-119.x

Yazdanbakhsh M, Sartono E, Kruize YCM, Kurniawan A, Partono F, Maizels RM, Schreuder G, Schipper R, de Vries René RP. 1995. HLA and elephantiasis in lymphatic filariasis. Hum Immunol [Internet]. [accessed 2019 Aug 24]. 44:58-61. Available from: https://linkinghub.else vier.com/retrieve/pii/019888599500059D

Yin Y, Li Y, Kerzic MC, Martin R, Mariuzza RA. 2011. Structure of a TCR with high affinity for self-antigen reveals basis for escape from negative selection: structure of autoimmune TCR bound to peptide-MHC. Embo J [Internet]. [accessed 2018 Oct 28]. 30:1137-48. Available from: http://emboj.embopress.org/cgi/doi/10.1038/emboj.2011.21

Yoshitake S, Kimura A, Okada M, Yao T, Sasazuki T. 1999. HLA class II alleles in Japanese patients with inflammatory bowel disease. Tissue Antigens. 53:350-58.

Yuliwulandari R, Kashiwase K, Nakajima H, Uddin J, Susmiarsih TP, Sofro ASM, Tokunaga K. 2009. Polymorphisms of HLA genes in Western Javanese (Indonesia): close affinities to Southeast Asian populations. Tissue Antigens [Internet]. [accessed 2018 Oct 26]. 73:46-53. doi:10.1111/ j.1399-0039.2008.01178.x

Yuliwulandari R, Kristin E, Prayuni K, Sachrowardi Q, Suyatna FD, Menaldi SL, Wichukchinda N, Mahasirimongkol S, Cavallari LH. 2017. Association of the HLA-B alleles with carbamazepineinduced Stevens-johnson syndrome/toxic epidermal necrolysis in the Javanese and Sundanese population of Indonesia: the important role of the HLA-B75 serotype. Pharmacogenomics [Internet]. [accessed 2019 Aug 21]. 18:1643-48. Available from: https://www.futuremedicine. com/doi/10.2217/pgs-2017-0103

Yuliwulandari R, Rochani JT, Indrawati I. 2010a. Genotype, serology and supertype classification of HLA class I in the Javanese. Jurnal Kedokteran YARSI 18:86-93.

Yuliwulandari R, Sachrowardi Q, Nakajima H, Kashiwase K, Hirayasu K, Mabuchi A, Sofro ASM, Tokunaga K. 2010b. Association of HLA-A, -B, and -DRB1 with pulmonary tuberculosis in western Javanese Indonesia. Hum Immunol [Internet]. [accessed 2018 Oct 27]. 71:697-701. Available from: http://linkinghub.elsevier.com/retrieve/pii/S0198885910001084

Zhang T, Xiao Y, Wang Y, Li Y, Zhang L, Chen C, Wang H. 2018. Single-tube multiplex real-time PCR assay for rapid and reliable detection of $H L A-A^{\star} 31: 01$ allele. Pharmacogenomics. 19:837-46.

Zhao Y, Wang J, Tanaka T, Hosono A, Ando R, Soeripto S, Triningsih FXE, Triono T, Sumoharjo S, Astuti EYW, et al. 2012. Association between HLA-DQ genotypes and haplotypes vs helicobacter pylori infection in an Indonesian population. Asian Pac J Cancer Prev [Internet]. [accessed 2019 Aug 24]. 13:1247-51. Available from: http://koreascience.or.kr/journal/view.jsp?kj= POCPA9\&py $=2012 \& v n c=v 13 n 4 \$ 1247$

Zhou X-J, Lv J-C, Zhao M-H, Zhang H. 2010. Advances in the genetics of anti-glomerular basement membrane disease. Am J Nephrol [Internet]. [accessed 2019 Aug 27]. 32:482-90. Available from: https://www.karger.com/Article/FullText/321324 
Zhou Z, Jensen PE. 2013. Structural characteristics of HLA-DQ that may impact DM editing and susceptibility to type-1 diabetes. Front Immunol [Internet]. [accessed 2018 Oct 28]. 4. Available from: http://journal.frontiersin.org/article/10.3389/fimmu.2013.00262/abstract

Zimdahl H, Schiefenhovel W, Kayser M, Roewer L, Nagy M. 1999. Towards understanding the origin and dispersal of austronesians in the Solomon Sea: HLA class II polymorphism in eight distinct populations of Asia-Oceania. Eur J Immunogenet [Internet]. [accessed 2018 Oct 27]. 26:405-16. doi:10.1046/j.1365-2370.1999.00183.x 
ISSubmit an article $\nabla$ A Subscribe 65

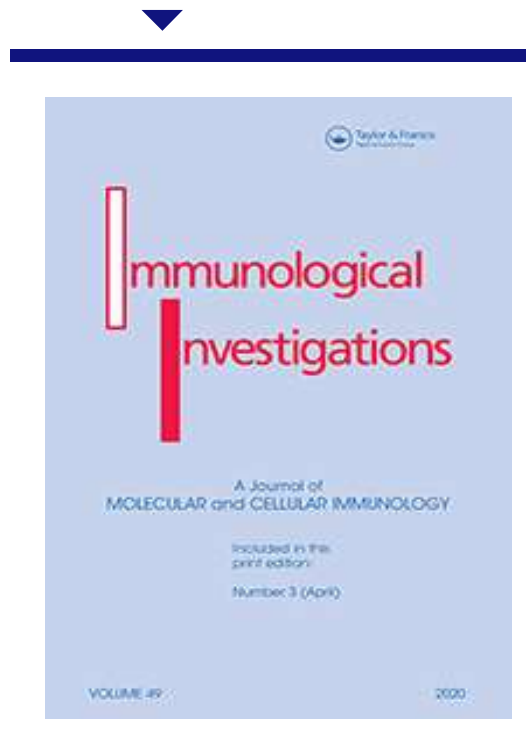

\section{Immunological Investigations}

A Journal of Molecular and Cellular Immunology

2018 Impact Factor

2.687

Publish open access in this journal

Advanced search

Submit an article New content alerts $\$$ RSS Subscribess Citation search

E Current issue $\equiv$ Browse list of issues in Explore

This journal 


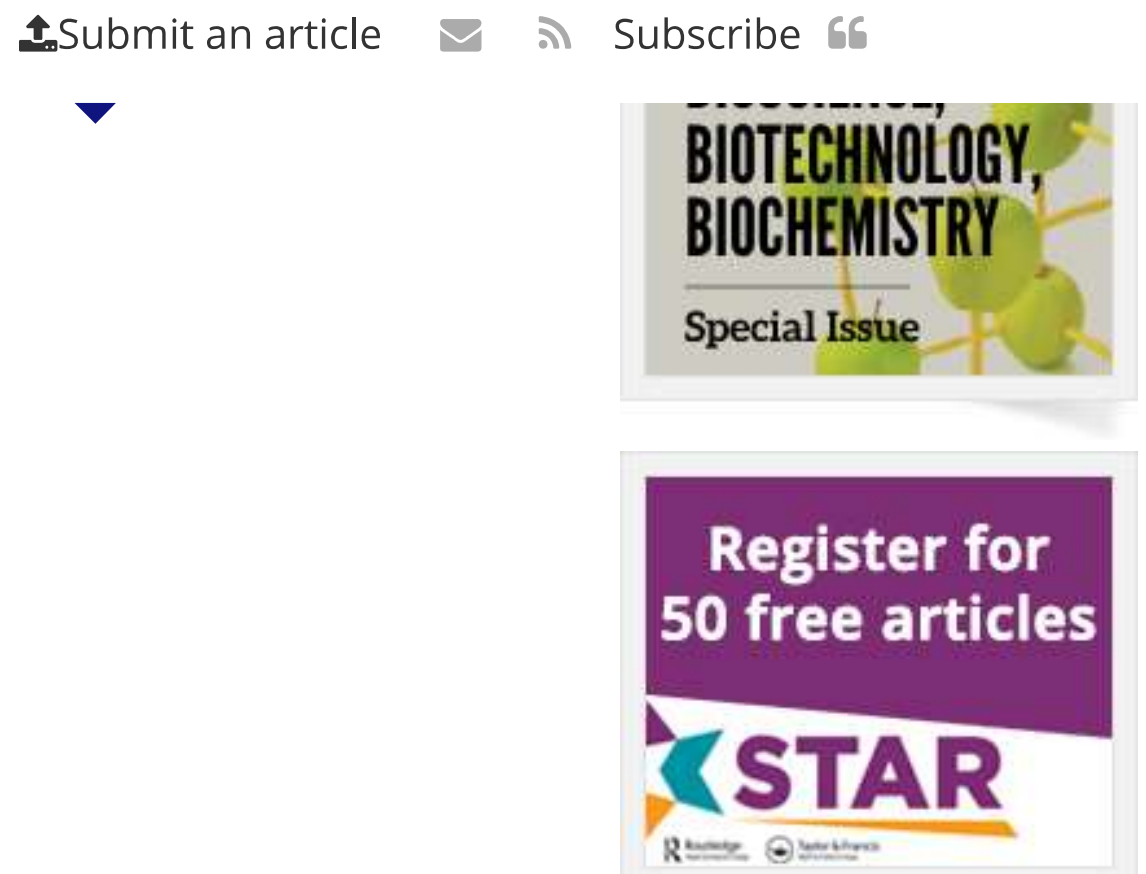

\section{Latest articles}

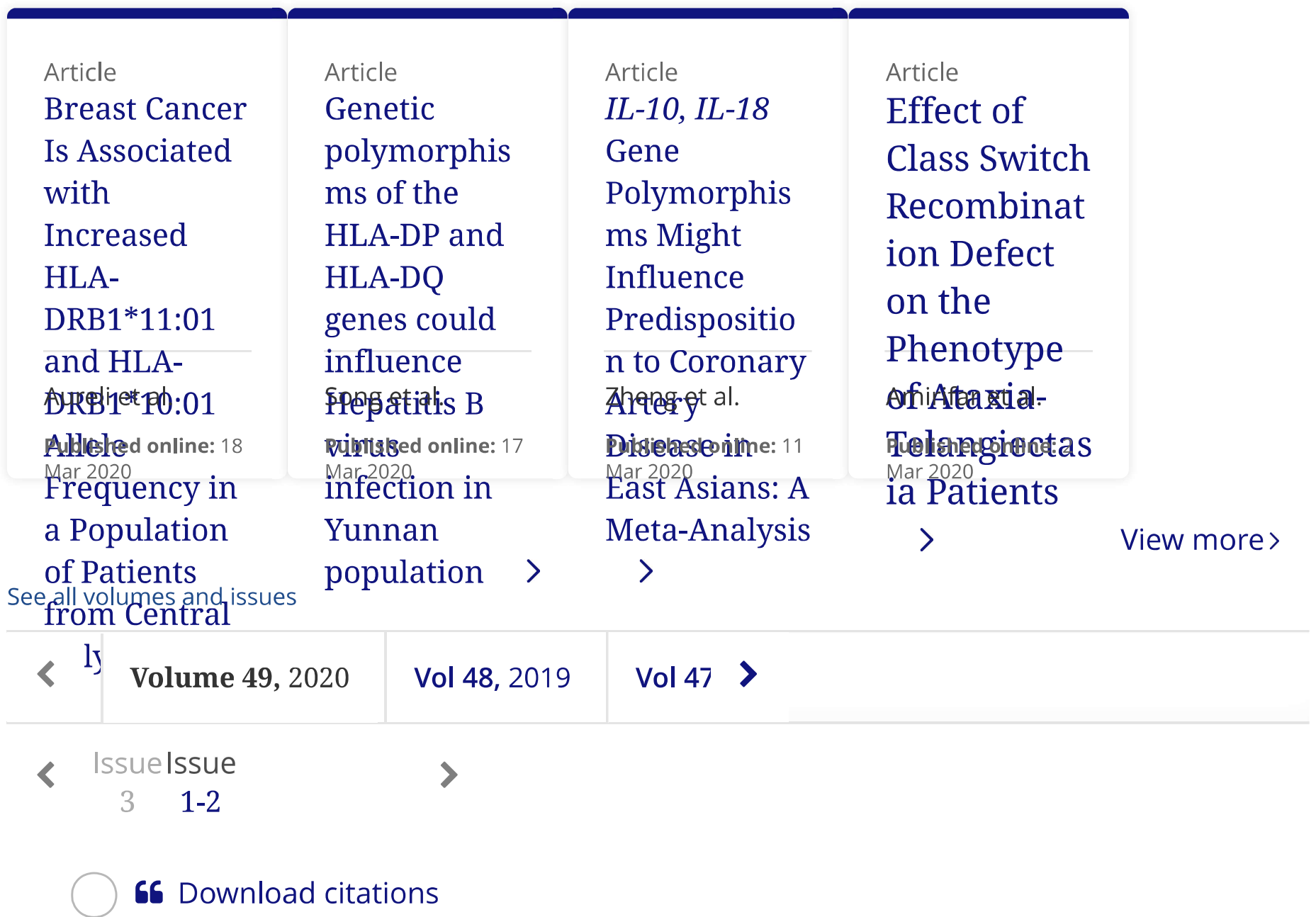

Original Articles 


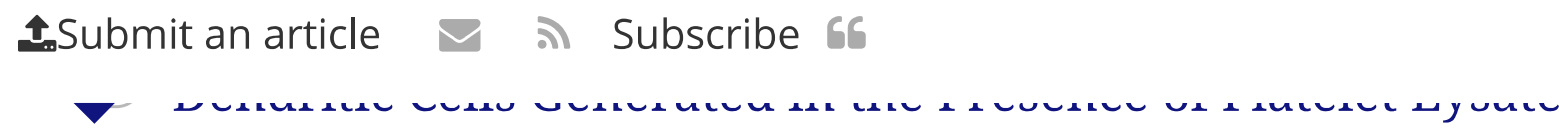

Have a Reduced Type 1 Polarization Capacity >

Nataša Tešić, Iza Pekle Simonič, Katja Roškar, Primož Rožman \& Urban Švajger

Pages: 215-231

Published online: 07 Jun 2019

\begin{tabular}{l|l|l}
92 & 0 & 1
\end{tabular}

Views CrossRef citations Altmetric

\section{Article}

Deficiency of Selected Cathepsins Does Not Affect the Inhibitory Action of ECTV on Immune Properties of Dendritic Cells >

Magdalena Bossowska-Nowicka, Matylda B. Mielcarska, Justyna Struzik, Agnieszka Jackowska-Tracz, Michał Tracz, Karolina P. Gregorczyk-Zboroch, Małgorzata Gieryńska, Felix N. Toka \& Lidia Szulc-Dąbrowska

Pages: 232-248

Published online: 26 Jun 2019

\begin{tabular}{l|l|l}
10 & 0 & 1
\end{tabular}

Views CrossRef citations Altmetric

\section{Article}

Interruption of Autophagosome Formation in Cardiovascular Disease, an Evidence for Protective Response of Autophagy > Hany Khalil, Ahmed I. Abd El Maksoud, Amira Alian, Waleed A. El-Hamady, Ahmed A. Daif, Ahmed M. Awad \& Adel A. Guirgis

Pages: 249-263

Published online: 02 Jul 2019

\begin{tabular}{l|l|l}
102 & 3 & 0
\end{tabular}

\begin{tabular}{l|l|l} 
Views & CrossRef citations & Altmetric
\end{tabular}

\section{Article}

A Comprehensive Profile of Chemokine Gene Expression in the Tissues of the Female Reproductive Tract in Mice > 


\title{
Isubmit an article $\nabla$ S Subscribe \\ Published online: 20 Aug 2019

\begin{tabular}{l|l|l}
64 & 0 & 2 \\
Views & CrossRef citations & Altmetric
\end{tabular}

\section{Article}

Methylation of Specific CpG Sites in $I L-1 \beta$ and IL1R1 Genes is Affected by Hyperglycaemia in Type 2 Diabetic Patients >

\author{
Pages: 287-298 \\ Published online: 03 Sep 2019 \\ \begin{tabular}{l|l|l}
42 & 1 & 0
\end{tabular} \\ Views CrossRef citations Altmetric
}

Naeimeh Roshanzamir \& Vahideh Hassan-Zadeh

\section{Article}

Delay in the Diagnosis of APECED: A Case Report and Review of Literature from Iran >

Mahnaz Jamee, Seyed Alireza Mahdaviani, Davood Mansouri, Gholamreza Azizi, Nematollah Joneidi, Hosseinali Ghaffaripour, Shabnam Eskandarzade, Mehdi Ghaini, Majid Marjani, Afshin Moniri, Mélanie Migaud, Jl Casanova, Anne Puel \& Aliakbar Velayati

Pages: 299-306

Published online: 07 Oct 2019

\begin{tabular}{l|l|l}
84 & 0 & 0
\end{tabular}

Views CrossRef citations Altmetric

\section{Article}

A Novel CD40L Mutation Associated with X-Linked Hyper IgM Syndrome in a Chinese Family >

Liangshan Li, Jing Ji, Mengmeng Han, Yinglei Xu, Xiao Zhang, Wenmiao Liu \& Shiguo Liu

Pages: 307-316

Published online: 12 Aug 2019 


\section{Reviews}

\section{Review}

\section{The Laboratory Role in anti-TNF Biological Therapy Era >}

Valentina Grossi, Francesca Gulli, Maria Infantino, Annunziata Stefanile, Cecilia Napodano, Maurizio Benucci, Krizia Pocino, Francesca Li Gobbi, Arianna Damiani, Antonella Di Pino, Mariangela Manfredi, Mariapaola Marino, Valerio Basile, Gian Ludovico Rapaccini \& Umberto Basile

Pages: 317-332

Published online: 12 Jul 2019

\begin{tabular}{l|l|l}
59 & 2 & 1 \\
Views & CrossRef citations & Altmetric
\end{tabular}

Review

Indonesians Human Leukocyte Antigen (HLA) Distributions and Correlations with Global Diseases >

Krisnawan Andy Pradana, Michael Anekson Widjaya \& Mariana Wahjudi

Pages: 333-363

Published online: 24 Oct 2019

\begin{tabular}{l|l|l}
45 & 1 & 0
\end{tabular}

Views CrossRef citations Altmetric

\section{Explore}

\section{Most read articles Most cited articles 6 Open access articles}


Journal

\section{Immunological Investigations > \\ A Journal of Molecular and Cellular Immunology}

This journal

\section{Editorial board}

\section{EDITOR}

Kate Rittenhouse-Olson, krolson@buffalo.edu - Department of Biotechnical and Clinical Laboratory Sciences, State University of New York at Buffalo, Buffalo, NY, USA

\section{ASSOCIATE EDITOR}

Ernesto G. Denardin - State University of New York at Buffalo, Buffalo, NY, USA

\section{EDITORIAL COMMITTEE}

M. Zouhair Atassi - Baylor College of Medicine, Houston, TX, USA

\section{EDITORIAL ADVISORY BOARD}

A. ALMOGREN - King Saud University, Riyadh, Saudi Arabia

D. AMSTERDAM - Erie County Medical Center, Buffalo, NY, USA

T. CHODON - Roswell Park Cancer Institute, Buffalo, NY, USA

J. CRANE - University at Buffalo, Buffalo, NY, USA

R.D. DZIAK - University at Buffalo, Buffalo, NY, USA

N. EGILMEZ - University of Louisville, Louisville, KY, USA

S. EVANS - Roswell Park Cancer Institute, Buffalo, NY, USA

S. FERRONE - Harvard University, Cambridge, MA, USA

S. GAFFEN - University of Pittsburgh, Pittsburgh, PA, USA

L. GARRETT-SINHA - State University of New York at Buffalo, Buffalo, NY, USA

S. GERBER - University of Rochester Medical Center, Rochester, NY, USA

V.V. GLINSKY - Department of Biochemistry, University of Missouri, Columbia, MO,

J. HEIMBURG-MOLINARO - Harvard University, Cambridge, MA, USA 
K.L. KIRKWOOD - University of Michigan, Ann Arbor, MI, USA

R.C. KOYA - Roswell Park Cancer Institute, Buffalo, NY, USA

P.T. LOVERDE - UT Health San Antonio, San Antonio, TX, USA

L.D. MASTRANDREA - University at Buffalo, Buffalo, NY USA

R. MOLINARO - Siemans Healthcare Diagnostics Inc., Newark, DE, USA

N.D. NADER - Veterans Administration Western New York, Buffalo, NY, USA

R. NEZLIN - The Weizmann Institute of Science, Rehovot, Israel

K. ODUNSI - Roswell Park Comprehensive Cancer Center, Buffalo, NY, USA

B.E. OSTROV - Albany Medical Center, Albany, NY, USA

S. QUATAERT - University of Rochester Medical Center, Rochester, NY, USA

B.S. RABIN - Presbyterian University Hospital, Pittsburgh, PA, USA

E. REPASKY - Roswell Park Cancer Institute, Buffalo, NY, USA

J. ROBERT - University of Rochester Medical Center, Rochester, NY, USA

N.R. ROSE - Johns Hopkins University, Baltimore, MD, USA

S.A. SCHWARTZ - Buffalo General Hospital, Buffalo, NY, USA

G. SHENOY - University of Buffalo, Buffalo, NY, USA

D. N. TAUB - National Institute on Aging, Baltimore, MD USA

Y. THANAVALA - Roswell Park Cancer Institute, Buffalo, NY, USA

P. WALLACE - Roswell Park Cancer Institute, Buffalo, NY, USA

C. XU - JiangNan University, China

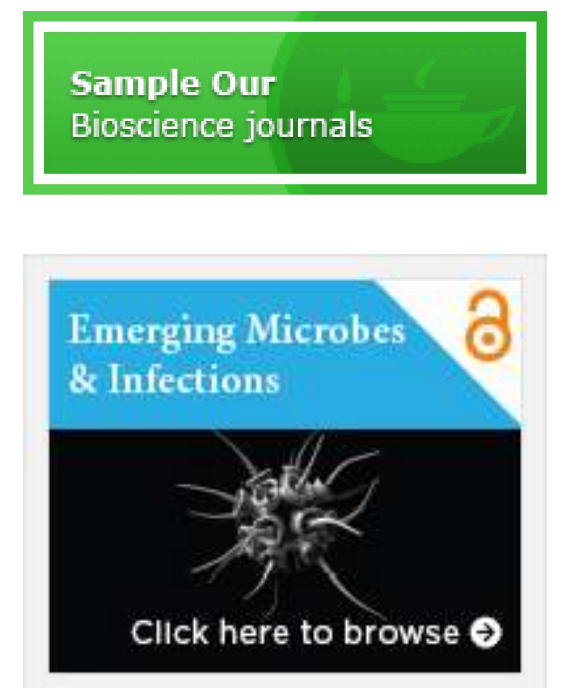




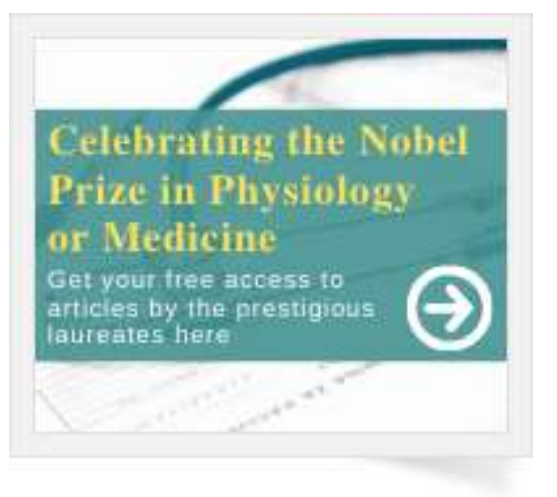

Information for

Authors

Editors

Librarians

Societies

Help and info

Help \& contact

Newsroom

Commercial services

All journals
Open access

Overview

Open journals

Open Select

Cogent OA

Keep up to date

Register to receive personalised research and resources by email

Sign me up

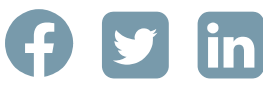

Yoube

Copyright (c) 2020 Informa UK Limited Privacy policy Cookies Terms \& conditions Accessibility

Registered in England \& Wales No. 3099067

5 Howick Place | London | SW1P 1WG 
Journal

\section{Immunological Investigations > \\ A Journal of Molecular and Cellular Immunology}

\section{This journal}

\section{Aims and scope}

Aims \& Scope: Disseminating immunological developments on a worldwide basis, Immunological Investigations encompasses all facets of fundamental and applied immunology, including immunohematology and the study of allergies. This journal provides information presented in the form of original research articles and book reviews, giving a truly in-depth examination of the latest advances in molecular and cellular immunology.

Publication office: Taylor \& Francis, Group, 530 Walnut Street, Suite 850, Philadelphia, PA 19106.

Sample Our

Medicine, Dentistry, Nursing \&

Allied Health journals

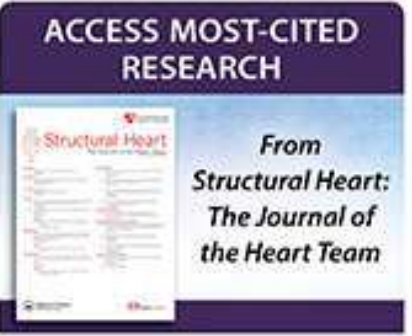




\section{SJR}

\section{Immunological Investigations}

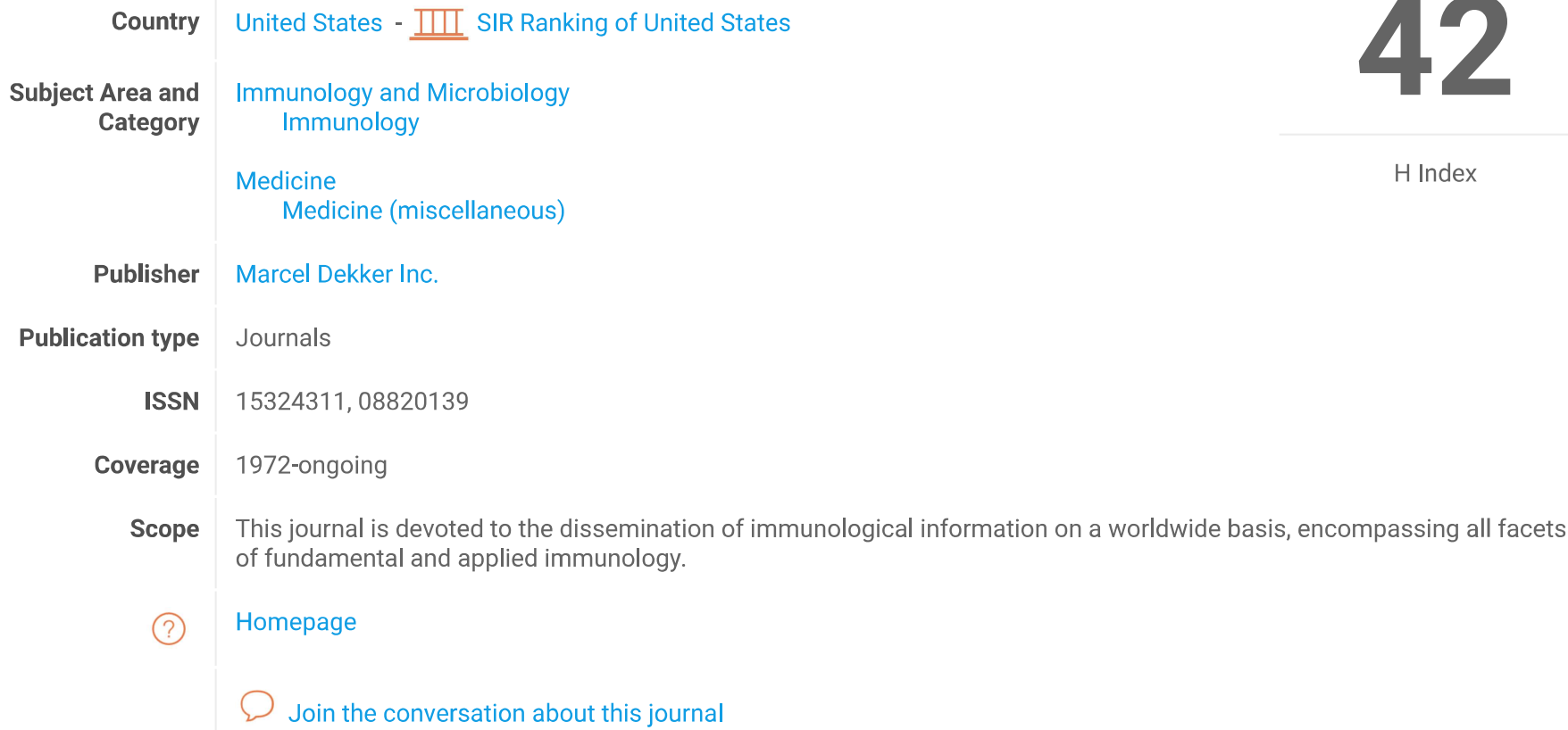

Quartiles

Medicine (miscellaneous)
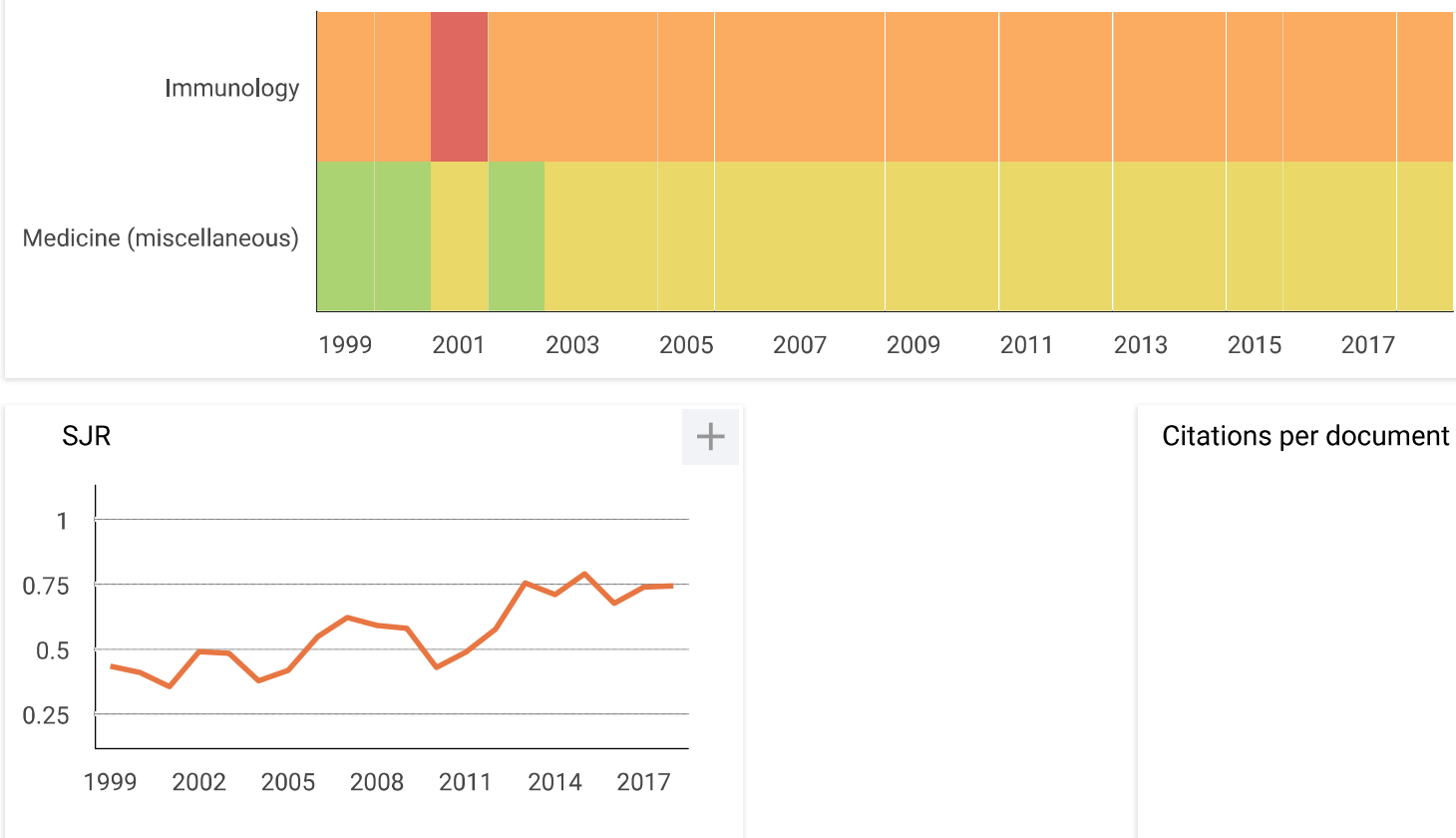

Citations per document

Total Cites

Self-Cites 

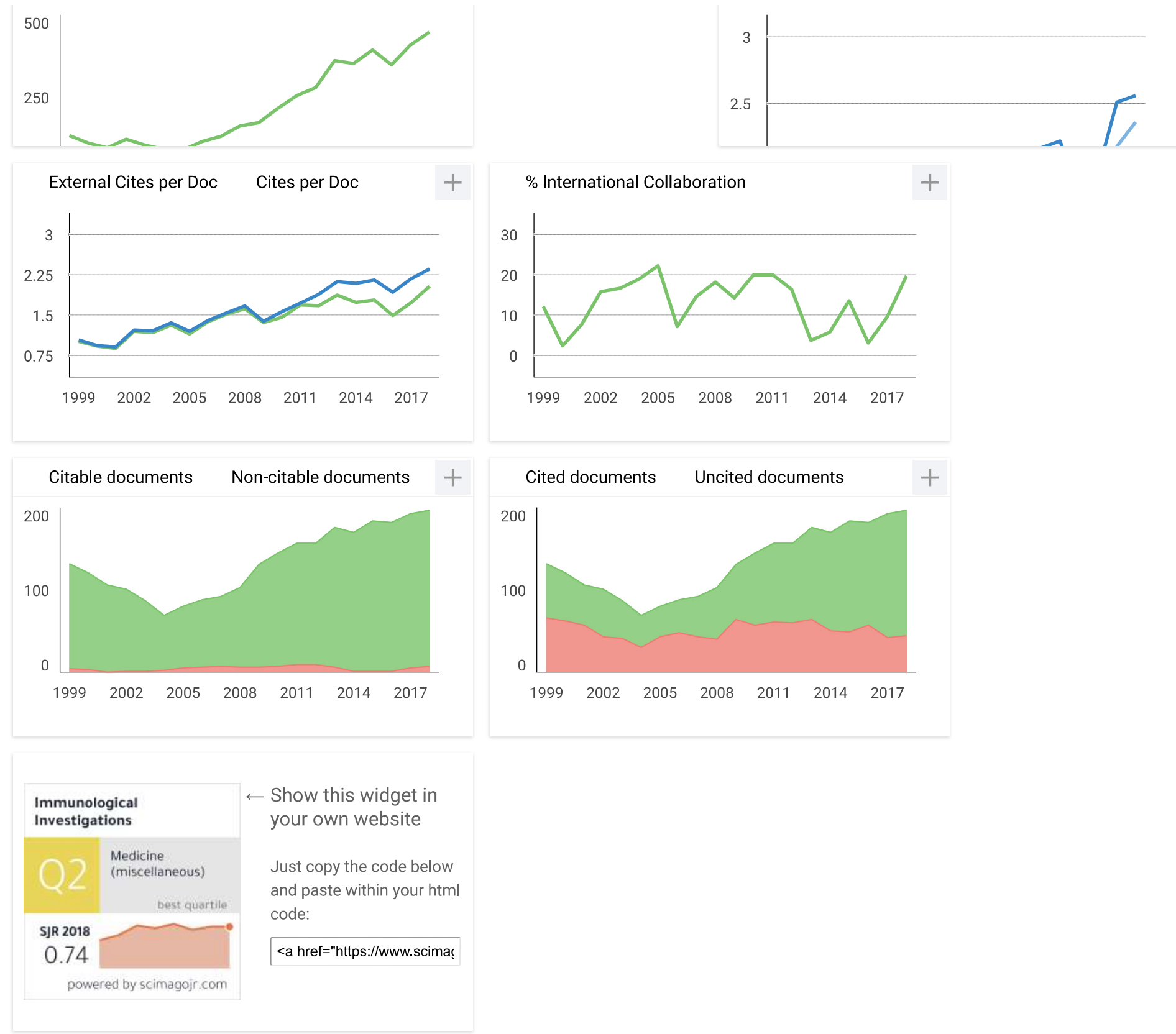

\section{Low Cost Journal Publication}

Research Paper, Review Paper, Genuine, Quick Response, High Impact Factor

ephjournal.org

\section{Leave a comment}

Name 


\section{Email}

(will not be published)

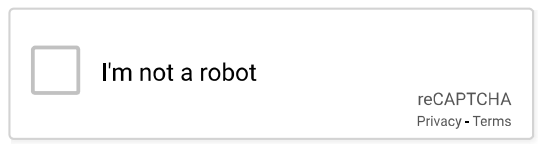

Submit

The users of Scimago Journal \& Country Rank have the possibility to dialogue through comments linked to a specific journal. The purpose is to have a forum in which general doubts about the processes of publication in the journal, experiences and other issues derived from the publication of papers are resolved. For topics on particular articles, maintain the dialogue through the usual channels with your editor.

Developed by:

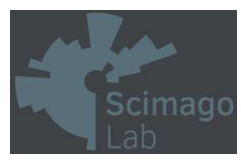

Follow us on @ScimagoJR
Powered by:

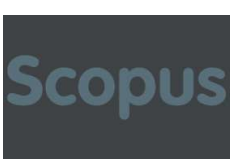

Scimago Lab, Copyright 2007-2020. Data Source: Scopus $®$ 
Journal

\section{Immunological Investigations > \\ A Journal of Molecular and Cellular Immunology}

This journal

\section{Journal information}

Print ISSN: 0882-0139 Online ISSN: 1532-4311

8 issues per year

Immunological Investigations is abstracted/indexed in:

- Adis International Ltd.

- Pharmacoeconomics and Outcomes News (Online)

- Reactions Weekly (Online)

- $\mathrm{CABI}$

- EBSCOhost

- Academic Search Alumni Edition/Complete/Elite/Premier/R\&D

- Advanced Placement Source

- Biological Abstracts (Online)

- Biomedical Reference Collection: Corporate Edition

- Current Abstracts

- Energy \& Power Source

- Science and Technology Collection

- TOC Premier (Table of Contents)

- Elsevier BV

- BIOBASE

- EMBASE, Priority

- International Atomic Energy Agency

- INIS Collection Search (International Nuclear Information System)

- National Library of Medicine

- PubMed/MEDLINE 
- Thomson Reuters

- Biological Abstracts (Online)

- BIOSIS Previews

- Current Contents

- Science Citation Index Expanded

- Web of Science

- VINITI RAN

- Referativnyi Zhurnal

Taylor \& Francis make every effort to ensure the accuracy of all the information (the "Content") contained in our publications. However, Taylor \& Francis, our agents, and our licensors make no representations or warranties whatsoever as to the accuracy, completeness, or suitability for any purpose of the Content. Any opinions and views expressed in this publication are the opinions and views of the authors, and are not the views of or endorsed by Taylor \& Francis. The accuracy of the Content should not be relied upon and should be independently verified with primary sources of information. Taylor \& Francis shall not be liable for any losses, actions, claims, proceedings, demands, costs, expenses, damages, and other liabilities whatsoever or howsoever caused arising directly or indirectly in connection with, in relation to, or arising out of the use of the Content. Terms \& Conditions of access and use can be found at http://www.tandfonline.com/page/terms-andconditions .

\section{Publication history}

\section{Currently known as:}

Immunological Investigations: A Journal of Molecular and Cellular Immunology (1985 - current)

\section{Formerly known as}

Immunological Communications (1972 - 1984)

Sample Our

Medicine, Dentistry, Nursing \&

Allied Health journals 


\section{TCT and TVT Registrants}

Structural Heart

a)

(ब)

ACTIVATE

Your full online

subscription to

Structural Heart

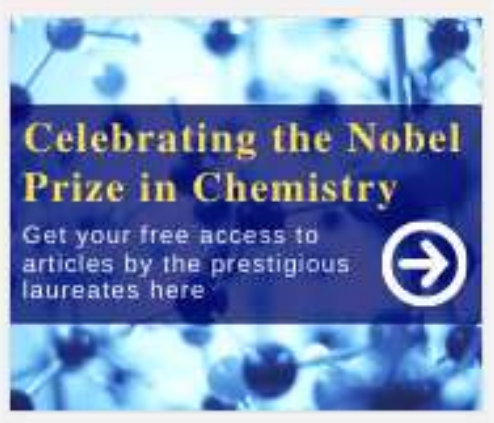

Information for

Authors

Editors

Librarians

Societies

Help and info

Help \& contact

Newsroom

Commercial services

All journals
Open access

Overview

Open journals

Open Select

Cogent OA

Keep up to date

Register to receive personalised research and resources by email

Sign me up

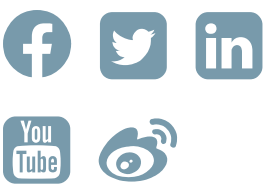

Copyright (c) 2020 Informa UK Limited Privacy policy Cookies Terms \& conditions Accessibility 


\section{Welcome to Taylor \& Francis Production: Immunological Investigations}

2 messages

IIMM-production@journals.tandf.co.uk <cats@taylorandfrancis.com> Reply-To: IIMM-production@journals.tandf.co.uk

To: mariana_wahyudi@staff.ubaya.ac.id

26 Sep 2019

Mariana Wahjudi,

Re: Indonesian Human Leukocyte Antigen (HLA) Distributions and Correlations with Global Diseases

Production tracking number: IIMM 1673771

Your paper for Immunological Investigations has been received by the Taylor \& Francis production department. As Production Editor I will work with you to oversee the production of your article from manuscript to publication. My contact details are given below.

- Please log in to CATS to complete your Author Publishing Agreement. Your user name and password are given below. If you have any questions on the process of completing your agreement, please contact me.

- You can check the status of your paper online through the CATS system at: https://cats.informa.com/PTS/in?ut= D808A124AF3C45A98A0C4466B2C70530

- Your User Name is: wahjudm

- Your Temporary Password is: Wahj3334_\# (You will need to change this the first time you log in)

- The DOI of your paper is: $10.1080 / 08820139.2019 .1673771$. Once your article has published online, it will be available at the following permanent link: https://doi.org/10.1080/08820139.2019.1673771 .

- For guidance on authors' rights, promoting your article, and other useful topics, please visit our Author Services website at: http://journalauthors.tandf.co.uk

Yours sincerely,

Cynthia Castro

Taylor \& Francis Group

4 Park Square

Milton Park

Abingdon

Oxon

OX14 4RN

UNITED KINGDOM

Email:IIMM-production@journals.tandf.co.uk

MARIANA WAHYUDI 190023 _<mariana_wahyudi@staff.ubaya.ac.id>

To: Krisnawan Andy P <krisnawan.andy@gmail.com>

Fri, Sep 27, 2019 at 5:58 PM

[Quoted text hidden] 
MARIANA WAHYUDI 190023 _<mariana_wahyudi@staff.ubaya.ac.id>

UBAYA

\section{Immunological Investigations - Please complete your author agreement}

2 messages

authoragreement@taylorandfrancis.com <authoragreement@taylorandfrancis.com>

To: mariana_wahyudi@staff.ubaya.ac.id

Thu, Sep 26, 2019 at 8:23 AM

Q Taylor S. Francis Group pie

Your Author Publishing Agreement (APA) with Taylor and Francis

Attention: Mariana Wahjudi

Hello,

In order to publish your article, "Indonesian Human Leukocyte Antigen

(HLA) Distributions and Correlations with Global Diseases", we ask that you

complete your Author Publishing Agreement. Please click the link below (or

copy the URL into your browser) to launch our online Author Publishing

Agreement portal. The process should take only a few minutes. In most

cases, you will receive immediate notice that your agreement is accepted

and will be able to download a copy of it for your records.

Please do not reply to this email. If you need immediate assistance concerning your article, please instead contact IIMM-production@journals.

tandf.co.uk.

Thank you.

\section{Start ॥}

https://authoragreement.taylorandfrancisgroup.com/Start/35fca230-0155-481a-9f4f-e8686113a421

(C) 2015 - Informa UK Limited, an Informa Group Company

MARIANA WAHYUDI 190023 _ <mariana_wahyudi@staff.ubaya.ac.id>

Fri, Sep 27, 2019 at 6:02 PM

To: Krisnawan Andy P <krisnawan.andy@gmail.com>

[Quoted text hidden] 


\section{PUBLISHING AGREEMENT}

This is an agreement under which you, the author, assign copyright in your article to Informa UK Limited registered in England under no. 1072954 trading as Taylor \& Francis Group, Registered Office: 5 Howick Place, London, SW1P 1WG (hereinafter 'Taylor \& Francis') to allow us to publish your article, including abstract, tables, figures, data, and supplemental material hosted by us, as the Version of Record (VoR) in the Journal for the full period of copyright throughout the world, in all forms and all media, subject to the Terms \& Conditions below.

Article (the "Article") entitled: Indonesian Human Leukocyte Antigen (HLA) Distributions and Correlations with Global Diseases Article DOI

Author(s): 10.1080/08820139.2019.1673771

To publish in the Journal:

Krisnawan Andy Pradana, Michael Anekson Widjaya, Mariana Wahjudi

Journal ISSN

$1532-4311$

\section{STATEMENT OF ORIGINAL COPYRIGHT OWNERSHIP / CONDITIONS}

In consideration of the publication of the Article, you hereby grant with full title guarantee all rights of copyright and related rights in the above specified Article as the Version of Scholarly Record which is intended for publication in all forms and all media (whether known at this time or developed at any time in the future) throughout the world, in all languages, for the full term of copyright, to take effect if and when the Article is accepted for publication in the Journal.

\section{ASSIGNMENT OF PUBLISHING RIGHTS}

I hereby assign Taylor \& Francis with full title guarantee all rights of copyright and related publishing rights in my article, in all forms and all media (whether known at this time or developed at any time in the future) throughout the world, in all languages, where our rights include but are not limited to the right to translate, create adaptations, extracts, or derivative works and to sub-license such rights, for the full term of copyright (including all renewals and extensions of that term), to take effect if and when the article is accepted for publication. If a statement of government or corporate ownership appears above, that statement modifies this assignment as described.

I confirm that I have read and accept the full Terms \& Conditions below including my author warranties, and have read and agree to comply with the Journal's policies on peer review and publishing ethics.

Signed and dated: 


\section{ASSIGNMENT OF COPYRIGHT: TERMS \& CONDITIONS}

\section{DEFINITION}

1. Your article is defined as comprising (a) your Accepted Manuscript (AM) in its final form; (b) the final, definitive, and citable Version of Record (VoR) including the abstract, text, bibliography, and all accompanying tables, illustrations, data, and media; and (c) any supplemental material hosted by Taylor \& Francis. This assignment and these Terms \& Conditions constitute the entire agreement and the sole understanding between you and us ('agreement'); no amendment, addendum, or other communication will be taken into account when interpreting your and our rights and obligations under this agreement, unless amended by a written document signed by both of us.

\section{TAYLOR \&FRANCIS' RESPONSIBILITIES}

2. If deemed acceptable by the Editors of the Journal, we shall prepare and publish your article in the Journal. We may post your accepted manuscript in advance of the formal publication of the VoR. We reserve the right to make such editorial changes as may be necessary to make the article suitable for publication, or as we reasonably consider necessary to avoid infringing third-party rights or breaching any laws; and we reserve the right not to proceed with publication for whatever reason

3. Taylor \& Francis will deposit your Accepted Manuscript (AM) to any designated institutional repository including PubMedCentral (PMC) with which Taylor \& Francis has an article deposit agreement; see 4 iv (a) below.

\section{RIGHTS RETAINED BY YOU AS AUTHOR}

4. These rights are personal to you, and your co-authors, and cannot be transferred by you to anyone else. Without prejudice to your rights as author set out below, you undertake that the fully reference-linked Version of Record (VOR) will not be published elsewhere without our prior written consent. You assert and retain the following rights as author(s):

i. The right to be identified as the author of your article, whenever and wherever the article is published, such rights including moral rights arising under $\S 77$, Copyright, Designs \& Patents Act 1988, and, so far as is legally possible, any corresponding rights we may have in any territory of the world.

ii. The right to retain patent rights, trademark rights, or rights to any process, product or procedure described in your article.

iii. The right to post and maintain at any time the Author's Original Manuscript (AOM; your manuscript in its original and unrefereed form; a 'preprint').

iv. The right to post at any time after publication of the VoR your AM (your manuscript in its revised after peer review and accepted for publication form; a 'postprint') as a digital file on your own personal or departmental website, provided that you do not use the VoR published by us, and that you include any amendments or deletions or warnings relating to the article issued or published by us; and with the acknowledgement: 'The Version of Record of this manuscript has been published and is available in $<$ JOURNAL TITLE> <date of publication> htto//www tandfonline com/<Article DOI>:

a. Please note that embargoes apply with respect to posting the AM to an institutional or subject repository. For further information, please see our list of journals with applicable embargo periods. For the avoidance of doubt, you are not permitted to post the final published paper, the VoR published by us, to any site, unless it has been published as Open Access on our website.

b. If, following publication, you or your funder pay an Article Publishing Charge for retrospective Open Access publication, you may then opt for one of three licenses: CCBY, CC BY-NC, or CC BY-NC-ND; if you do not respond, we shall assign a CC BY licence. All rights in the article will revert to you as author.

v. The right to share with colleagues copies of the article in its published form as supplied to you by Taylor \& Francis as a digital eprint or printed reprint on a non-commercial basis.

vi. The right to make printed copies of all or part of the article on a non-commercial basis for use by you for lecture or classroom purposes provided that such copies are not offered for sale or distributed in any systematic way, and provided that acknowledgement to prior publication in the Journal is given.

vii. The right, if the article has been produced within the scope of your employment, for your employer to use all or part of the article internally within the institution or company on a non-commercial basis provided that acknowledgement to prior publication in the Journal is given.

viii. The right to include the article in a thesis or dissertation that is not to be published commercially, provided that acknowledgement to prior publication in the Journal is given.

ix. The right to present the article at a meeting or conference and to distribute printed copies of the article to the delegates attending the meeting provided that this is not for commercial purposes and provided that acknowledgement to prior publication in the Journal is given.

$\mathrm{x}$. The right to use the article in its published form in whole or in part without revision or modification in personal compilations, or other publications of your own work, provided that acknowledgement to prior publication in the Journal is given.

xi. The right to expand your article into book-length form for publication provided that acknowledgement to prior publication in the Journal is made explicit (see below). Where permission is sought to re-use an article in a book chapter or edited collection on a commercial basis a fee will be due, payable by the publisher of the new work. Where you as the author of the article have had the lead role in the new work (i.e., you are the author of the new work or the editor of the edited collection), fees will be waived. Acknowledgement to prior publication in the Journal should be made explicit (see below):

Acknowledgement: This <chapter or book $>$ is derived in part from an article published in <JOURNAL TITLE > <date of publication><copyright Taylor \& Francis>, available online: hito/ wovetandfonline com/<Article DOI>

If you wish to use your article in a way that is not permitted by this agreement, please contact permissionrequestatandf co.uk

\section{WARRANTIES MADE BY YOU AS AUTHOR}

5. You warrant that:

i. All persons who have a reasonable claim to authorship are named in the article as co-authors including yourself, and you have not 
fabricated or misappropriated anyone's identity, including your own.

ii. You have been authorized by all such co-authors to sign this agreement as agent on their behalf, and to agree on their behalf the priority of the assertion of copyright and the order of names in the publication of the article.

iii. The article is your original work, apart from any permitted third-party copyright material you include, and does not infringe any intellectual property rights of any other person or entity and cannot be construed as plagiarizing any other published work, including your own published work.

iv. The article is not currently under submission to, nor is under consideration by, nor has been accepted by any other journal or publication, nor has been previously published by any other journal or publication, nor has been assigned or licensed by you to any third party.

$v$. The article contains no content that is abusive, defamatory, libelous, obscene, fraudulent, nor in any way infringes the rights of others, nor is in any other way unlawful or in violation of applicable laws.

vi. Research reported in the article has been conducted in an ethical and responsible manner, in full compliance with all relevant codes of experimentation and legislation. All articles which report in vivo experiments or clinical trials on humans or animals must include a written statement in the Methods section that such work was conducted with the formal approval of the local human subject or animal care committees, and that clinical trials have been registered as applicable legislation requires.

vii. Any patient, service user, or participant (or that person's parent or legal guardian) in any research or clinical experiment or study who is described in the article has given written consent to the inclusion of material, text or image, pertaining to themselves, and that they acknowledge that they cannot be identified via the article and that you have anonymized them and that you do not identify them in any way. Where such a person is deceased, you warrant you have obtained the written consent of the deceased person's family or estate.

viii. You have complied with all mandatory laboratory health and safety procedures in the course of conducting any experimental work reported in your article; your article contains all appropriate warnings concerning any specific and particular hazards that may be involved in carrying out experiments or procedures described in the article or involved in instructions, materials, or formulae in the article; your article includes explicitly relevant safety precautions; and cites, if an accepted Standard or Code of Practice is relevant, a reference to the relevant Standard or Code

ix. You have acknowledged all sources of research funding, as required by your research funder, and disclosed any financial interest or benefit you have arising from the direct applications of your research.

$x$. You have obtained the necessary written permission to include material in your article that is owned and held in copyright by a third party, which shall include but is not limited to any proprietary text, illustration, table, or other material, including data, audio, video, film stills, screenshots, musical notation and any supplemental material.

xi. You have read and complied with our policy on publishing ethics.

xii. You have read and complied with the Journal's Instructions for Authors.

xiii. You have read and complied with our guide on peer review.

xiv. You will keep us and our affiliates indemnified in full against all loss, damages, injury, costs and expenses (including legal and other professional fees and expenses) awarded against or incurred or paid by us as a result of your breach of the warranties given in this agreement.

xv. You consent to allowing us to use your article for marketing and promotional purposes.

\section{GOVERNING LAW}

6. This agreement (and any dispute, proceeding, claim or controversy in relation to it) is subject to English law and the parties hereby submit to the exclusive jurisdiction of the Courts of England and Wales. 


\section{Your completed Author Publishing Agreement for "Indonesian Human Leukocyte Antigen (HLA) Distributions and Correlations with Global Diseases"} 1 message

authoragreement@taylorandfrancis.com <authoragreement@taylorandfrancis.com> To: mariana_wahyudi@staff.ubaya.ac.id

\section{Your completed Author Publishing Agreement (APA) with Taylor and} Francis

Attention: Mariana Wahjudi

Hello,

Your Author Publishing Agreement for "Indonesian Human Leukocyte Antigen (HLA) Distributions and Correlations with Global Diseases" has been completed. Please click the link below (or copy the URL into your browser) to access the system and download your signed agreement.

Should you have any question on this, you may contact IIMMproduction@journals.tandf.co.uk.

Thank you. 


\section{Your article proofs for review (ID\# IIMM 1673771)}

1 message

IIMM-production@journals.tandf.co.uk <cats@taylorandfrancis.com>

Sat, Oct 12, 2019 at 9:00 AM

Reply-To: IIMM-production@journals.tandf.co.uk

To: mariana_wahyudi@staff.ubaya.ac.id

12 Oct 2019

Proofs of your article(s) listed below are now available for review through the Central Article Tracking System (CATS) website:

- Journal: IIMM: Immunological Investigations

- Manuscript ID: 1673771 (LIMM-2019-0022.R1)

- Manuscript Title: Indonesians Human Leukocyte Antigen (HLA) Distributions and Correlations with Global Diseases

- By: Pradana; Widjaya; Wahjudi

Please approve these proofs, or return any corrections by 16 Oct 2019. Failure to do so may result in delay of your publication, reallocation to a later issue, or review and approval of your article by the journal's Editor-in-Chief.

- Please follow the link below to view the manuscript through the CATS system. https://cats.informa.com/PTS/in?ut= D808A124AF3C45A98A0C4466B2C70530

- Your User Name is: WAHJUDM

- Your Temporary Password is: Wahj9874\$\# (You will need to change this the first time you log in)

Once logged into CATS you will be able to view the 'My Manuscripts' page with the article(s) currently in production where you are listed as an author. Clicking on 'Review Proofs' will allow you to access your article. Please use the web form (if the corrections are fewer than 50 in number) to return any corrections to me. Instructions on how to use the web form can be found by clicking on the 'Proofing Guidelines for Authors' link located at the bottom of the window in which your proofs appear. Alternatively, send your corrections in an email to me or you can print the article and fax or post it to the address listed below.

When the article publishes, each author will receive 50 e-prints to share with colleagues. This will enable you to give any friend, colleague, or contact free access to an electronic version of your article.

Hardcopy reprints of your article are available with special pricing for authors, and authors may also order print copies of the issue in which the article appears. Orders may be placed by logging in to your CATS account and accessing the order form on the "Additional Actions" menu. If you have any questions on this process, please contact me.

PLEASE NOTE: The CATS system only supports Internet Explorer 6 (and later), or Firefox 3 (and later) browser software. Popup blockers should be disabled. If you have any difficulty using CATS, please contact me.

Thank you,

Cynthia Castro

Taylor \& Francis Group

4 Park Square

Milton Park

Abingdon

Oxon

OX14 4RN

UNITED KINGDOM

Email:IIMM-production@journals.tandf.co.uk 
MARIANA WAHYUDI 190023 _<mariana_wahyudi@staff.ubaya.ac.id>

\section{Submitted Corrections for Manuscript ID: IIMM 1673771}

1 message

IIMM-production@journals.tandf.co.uk <cats@taylorandfrancis.com>

Reply-To: IIMM-production@journals.tandf.co.uk

To: IIMM-production@journals.tandf.co.uk, mariana_wahyudi@staff.ubaya.ac.id

Wed, Oct 16, 2019 at 5:58 PM

This e-mail confirms that you have submitted the following corrections to your proofs. Please review the journal and article/content titles below to make sure they are correct.

If any of this information is incorrect, please contact the Production Editor for Immunological Investigations, Cynthia Castro, at IIMM-production@journals.tandf.co.uk.

- Journal: IIMM: Immunological Investigations

- Manuscript ID: 1673771

- Title: Manuscript Title: Indonesians Human Leukocyte Antigen (HLA) Distributions and Correlations with Global Diseases

- By: Pradana; Widjaya; Wahjudi

Comments from: Mariana Wahjudi

Date sent: 12 Oct 2019

Date returned: 16 Oct 2019

Correction\#: 1

Query\#:

Page\#:

Line\#: 1

Correction files have been uploaded

Correction files were uploaded with this submission. 


\section{Taylor \& Francis author update: congratulations, your article is published!}

6 messages

Taylor \& Francis <noreply@tandfonline.com>

Fri, Oct 25, 2019 at 1:54 PM

Reply-To: support@tandfonline.com

To: mariana_wahyudi@staff.ubaya.ac.id
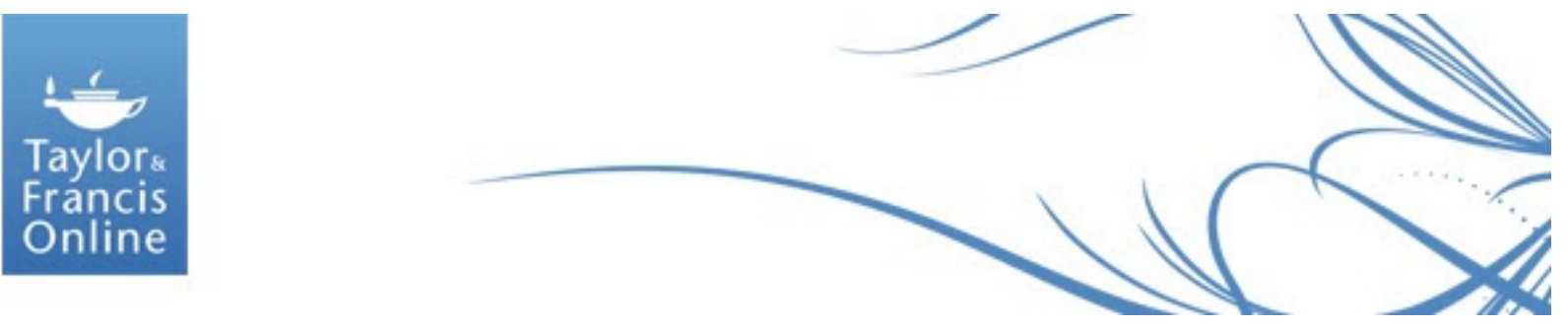

The online platform for Taylor \& Francis Group content

Author Services | FAQ | Twitter | Facebook

Dear Mariana Wahjudi,

Congratulations, we're delighted to let you know that your final published article (the Version of Record) is now on Taylor \& Francis Online.

Indonesians Human Leukocyte Antigen (HLA) Distributions and Correlations with Global Diseases 
Want to tell others you're published? Use your free eprints today

Every author at Taylor \& Francis (including all co-authors) gets 50 free online copies of their article to share with friends and colleagues as soon as their article is published. Your eprint link is now ready to use and is:

https://www.tandfonline.com/eprint/X5XGKZPSFMYSET82CTBU/ full?target=10.1080/08820139.2019.1673771

\section{$\mathbf{y} \mathbf{8}$}

You can paste this into your emails, on social media, or anywhere else you'd like others to read your article. Author feedback tells us this is a highly effective way of highlighting your research. Using this link also means we can track your article's downloads and citations, so you can measure its impact. Find out more about sharing your work, how you can work with us to highlight your article.

\section{Have you registered to access your Authored Works?}

If you haven't already done so, now is the time to register for your Authored Works, our dedicated center for all Taylor \& Francis published authors. Authored Works gives you instant access to your article, and is where you can go to see how many people have downloaded it, cited it and access your Altmetric data.

To access your Authored Works, you will need to register with the email address below:

mariana_wahyudi@staff.ubaya.ac.id

Once you've completed the quick registration you'll be sent an email asking you to confirm. Click on the verification link and you can then login (using the above email address) whenever you want to by going to Taylor \& Francis Online. Once you have logged in, click on "Your Account" at the top of the page to see the latest updates on your article.

\section{Next steps}

We'll be in touch as soon as your article is assigned to the latest issue of Immunological Investigations, but if you've any queries in the interim don't hesitate to get in touch via authorqueries@tandf.co.uk.

Kind regards,

Stewart Gardiner

Global Production Director, Journals

Taylor \& Francis Group

Interested in insights, tips, and updates for Taylor \& Francis

authors? Be part of our researcher community on:

Twitter

Facebook

Taylor \& Francis Author Services

Please do not reply to this email. To ensure that you receive your alerts and information from Taylor \& Francis Online, please add "alerts@tandfonline.com" and "info@tandfonline.com" to your safe senders list.

Taylor \& Francis, an Informa business.

Taylor \& Francis is a trading name of Informa UK Limited, registered in England under no. 1072954. Registered office: 5 Howick Place, London, SW1P 1WG. 


\title{
Taylor \& Francis author update: access to your article published in an issue of Immunological Investigations
}

\author{
4 messages
}

Taylor \& Francis < noreply@tandfonline.com>

Reply-To: support@tandfonline.com

To: mariana_wahyudi@staff.ubaya.ac.id

$\stackrel{x}{2}$

Taylor:

Francis

Online

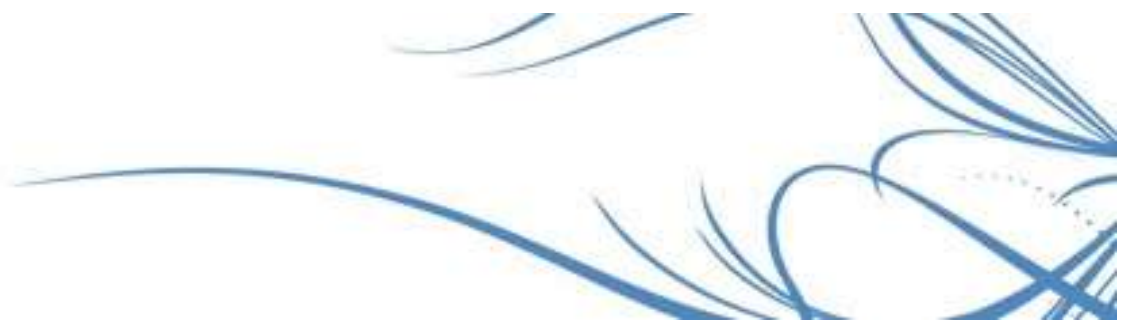

The online platform for Taylor \& Francis Group content

Author Services | FAQ | Twitter | Facebook

Dear Mariana Wahjudi,

Your article, Indonesians Human Leukocyte Antigen (HLA) Distributions and Correlations with Global Diseases, published in Immunological Investigations, Volume 49 Issue 3, is now available for you to access via tandfonline.com.

You will have permanent, free access to the final published version of your article via your Authored Works, our dedicated center for all Taylor \& Francis authors. This is where you can view all articles published in our journals, check how many people have viewed them, see their citations, and check your Altmetric data. Haven't registered for your Authored Works yet? Find out how. 
Have you used your free eprints yet?

Now you're published, you'll hopefully want to share your article with friends or colleagues. Every author at Taylor \& Francis (including all co-authors) gets 50 free online copies of their article to share with their networks. Your eprint link is now ready to use and is:

https://www.tandfonline.com/eprint/X5XGKZPSFMYSET82CTBU/ full?target=10.1080/08820139.2019.1673771

\section{$\mathbf{9} \mathbf{f}$}

You can share this any way you want, and author feedback tells us this is a highly effective way of highlighting your research. Using this link also means we can track your article's downloads and citations, so you can measure its impact. Find out more about sharing your work, and how you can work with us to highlight your article.

If you have any problems accessing your Taylor \& Francis Online account, or using your eprints, please contact us.

Kind regards,

Stewart Gardiner

Global Production Director, Journals

Taylor \& Francis Group

Interested in insights, tips, and updates for Taylor \& Francis

authors? Be part of our researcher community on:

Twitter

Facebook

Taylor \& Francis Author Services

Please do not reply to this email. To ensure that you receive your alerts and information from Taylor \& Francis Online, please add "alerts@tandfonline.com" and "info@tandfonline.com" to your safe senders list.

Taylor \& Francis, an Informa business.

Taylor \& Francis is a trading name of Informa UK Limited, registered in England under no. 1072954. Registered office: 5 Howick Place, London, SW1P 1WG.

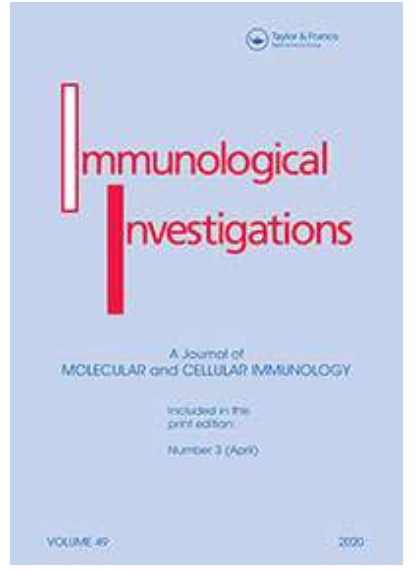

Taylor \& Francis

MARIANA WAHYUDI 190023 _<mariana_wahyudi@staff.ubaya.ac.id> Sat, Mar 14, 2020 at 10:03 AM To: Krisnawan Andy P <krisnawan.andy@gmail.com>, Michael Anekson Widjaya <michaelanekson@gmail.com>

[Quoted text hidden]

Krisnawan Andy P <krisnawan.andy@gmail.com>

Sat, Mar 14, 2020 at 10:04 AM

To: MARIANA WAHYUDI 190023 _<mariana_wahyudi@staff.ubaya.ac.id>

Cc: Michael Anekson Widjaya <michaelanekson@gmail.com>

Well received with thanks

[Quoted text hidden]

MARIANA WAHYUDI 190023 _mariana_wahyudi@staff.ubaya.ac.id>

To: Krisnawan Andy P <krisnawan.andy@gmail.com>

Sat, Mar 14, 2020 at 10:20 AM

Cc: Michael Anekson Widjaya <michaelanekson@gmail.com>

You are welcome.

[Quoted text hidden] 